TECHNICAL WORKING PAPER SERIES

\title{
SOLVING GENERAL EQUILIBRIUM MODELS WITH INCOMPLETE MARKETS AND MANY ASSETS
}

\author{
Martin D. D. Evans \\ Viktoria Hnatkovska \\ Technical Working Paper 318 \\ http://www.nber.org/papers/T0318 \\ NATIONAL BUREAU OF ECONOMIC RESEARCH \\ 1050 Massachusetts Avenue \\ Cambridge, MA 02138 \\ October 2005
}

We thank Jonathan Heathcote for valuable comments and the National Science Foundation for financial support. The views expressed herein are those of the author(s) and do not necessarily reflect the views of the National Bureau of Economic Research.

(C2005 by Martin D. D. Evans and Viktoria Hnatkovska. All rights reserved. Short sections of text, not to exceed two paragraphs, may be quoted without explicit permission provided that full credit, including () notice, is given to the source. 
Solving General Equilibrium Models with Incomplete Markets and Many Assets

Martin D. D. Evans and Viktoria Hnatkovska

NBER Technical Working Paper No. 318

October 2005

JEL No. C68, D52, G11

\begin{abstract}
This paper presents a new numerical method for solving general equilibrium models with many assets. The method can be applied to models where there are heterogeneous agents, time-varying investment opportunity sets, and incomplete markets. It also can be used to study models where the equilibrium dynamics are non-stationary. We illustrate how the method is used by solving a one-and two-sector versions of a two--country general equilibrium model with production. We check the accuracy of our method by comparing the numerical solution to the one-sector model against its known analytic properties. We then apply the method to the two-sector model where no analytic solution is available.
\end{abstract}

Martin D. D. Evans

Georgetown University

Department of Economics

Washington, DC 20057

and NBER

evansm1@georgetown.edu

Viktoria Hnatkovska

Georgetown University

Department of Economics

Washington, DC 20057

vh6@georgetown.edu 


\section{Introduction}

This paper presents a new numerical method for solving general equilibrium models with many assets. The method can be applied to models where there are heterogeneous agents, time-varying investment opportunity sets, and incomplete markets. It also can be used to study models where the equilibrium dynamics are non-stationary. In this paper, we illustrate how the method is used by solving a one- and two-sector versions of a two-country general equilibrium model with production. We check the accuracy of our method by comparing the numerical solution to the one-sector model against its known analytic properties. We then apply the method to the two-sector model where no analytic solution is available. A detailed analysis of this model is provided in a companion paper, Evans and Hnatkovska (2005).

Our approach combines perturbation methods with continuous-time approximations. In so doing, we contribute to the literature along several dimensions. First, relative to the finance literature, our method delivers optimal portfolios in a discrete-time general equilibrium setting in which returns are endogenously determined. It also enables us to characterize the dynamics of returns and the stochastic investment opportunity set as functions of macroeconomic state variables. ${ }^{2}$ Second, relative to macroeconomics literature, portfolio decisions are derived without assuming complete asset markets, separable preferences or constant returns to scale in production. ${ }^{3}$

Our solution method also relates to the literature on perturbation methods as developed and applied in Judd and Guu (1993, 1997), Judd (1998) and further discussed in Collard and Juillard (2001), Jin and Judd (2002), Schmitt-Grohe and Uribe (2004) among others. These methods extend solution techniques relying on linearizations by allowing for second- and higher-order terms in the approximations of the policy functions. Unfortunately, these methods can only be used in applications that omit a key feature of models with portfolio choice: namely, the conditional heteroskedasticity of the state vector that captures the time-varying nature of the investment opportunity set. Existing methods are also unable to accommodate the non-stationary dynamics that arise endogenously when markets are incomplete.

The paper is structured as follows. Section 1 presents the one-sector version of the model we

\footnotetext{
${ }^{2} \mathrm{~A}$ number of approximate solution methods have been developed in partial equilibrium frameworks. Kogan and Uppal (2000) approximate portfolio and consumption allocations around the solution for a log-investor. Berberis (2000), Brennan, Schwartz, and Lagnado (1997) use discrete-state approximations. Brandt, Goyal, and Santa-Clara (2001) solve for portfolio policies by applying dynamic programming to an approximated simulated model. Brandt and Santa-Clara (2004) expand the asset space to include asset portfolios and then solve for the optimal portfolio choice in the resulting static model.

${ }^{3}$ Solutions to portfolio problems with complete markets are developed in Heathcote and Perri (2004), Serrat (2001), Kollmann (2005), Baxter, Jermann and King (1998), Uppal (1993). Pesenti and van Wincoop (1996), Engel and Matsumoto (2004) analyze equilibrium portfolios in incomplete markets.
} 
use to illustrate our solution method. Section 2 describes the method in detail. Section 3 presents and compares the numerical solution of the model to its analytic counterpart. Section 4 presents the two-sector version of the model and examines its equilibrium properties. Section 5 concludes.

\section{The One Sector Model}

This section describes the one-sector version of the model we employ to illustrate our solution method. It is a standard international asset pricing model with portfolio choice and builds upon Danthine and Donaldson's (1994) formulation of an asset pricing model with production. We consider a frictionless production world economy consisting of two symmetric countries, called home (H) and foreign (F). Each country is populated by a continuum of identical households who supply their labor inelastically to domestic firms producing a single good freely traded between the two countries. Firms are perfectly competitive and issue equity that is traded on the world stock market.

\section{$1.1 \quad$ Firms}

Our firms are infinitely lived. They issue equity claims to the stream of their dividends, and households can use this equity for their saving needs. Each firm owns capital and undertakes independent investment decisions. A representative firm in the $\mathrm{H}$ country starts period $t$ with the stock of capital $K_{t}$ and equity liability $A_{t}=1$. Period $t$ production is

$$
Y_{t}=Z_{t} K_{t}^{\theta}
$$

with $\theta>0$. The output produced by firms in the F country, $\hat{Y}_{t}$, is given by an identical production

function using foreign capital $\hat{K}_{t}$, and productivity $\hat{Z}_{t}$. (Hereafter we use "^" to denote foreign variables.) The goods produced by $\mathrm{H}$ and $\mathrm{F}$ firms are identical and can be costlessly transported between countries. Under these conditions, the law of one price must prevail to eliminate arbitrage opportunities.

At the beginning of period $t$, each firm observes the productivity realization, produces output and uses the proceeds to finance investment $I_{t}$ and to pay dividends to the shareholders. We assume that firms allocate output to maximize the value of the firm to its shareholders every period. Let $P_{t}$ denote the ex-dividend price of a share in the representative $\mathrm{H}$ firm at the start of period $t$, and let $D_{t}$ be the dividend per share paid at $t$. The value of the firm at the start of period $t$ is $P_{t}+D_{t}$, 
and the optimization problem it faces can be summarized as

$$
\max _{I_{t}}\left(D_{t}+P_{t}\right)
$$

subject to

$$
\begin{aligned}
K_{t+1} & =(1-\delta) K_{t}+I_{t}, \\
D_{t} & =Z_{t} K_{t}^{\theta}-I_{t},
\end{aligned}
$$

where $\delta>0$ is the depreciation rate on physical capital. The representative firm in the F country solves an analogous problem; that is to say they choose investment $\hat{I}_{t}$ to maximize $\hat{D}_{t}+\hat{P}_{t}$, where $\hat{P}_{t}$ is the ex-dividend price of a share and $\hat{D}_{t}$ is the dividend per share paid at $t$.

Let $z_{t} \equiv\left[\ln Z_{t}, \ln \hat{Z}_{t}\right]^{\prime}$ denote the state of productivity in period $t$. We assume that $z_{t}$ follows an $\operatorname{AR}(1)$ process:

$$
z_{t}=a z_{t-1}+e_{t}
$$

where $e_{t}$ is a $2 \times 1$ vector of i.i.d. mean zero shocks with covariance $\Omega_{e}$.

\subsection{Households}

Each country is populated by a continuum of households who have identical preferences. The preferences of households in the $\mathrm{H}$ country are defined in terms of $\mathrm{H}$ consumption $C_{t}$, and are given by

$$
\mathbb{U}_{t}=\mathbb{E}_{t} \sum_{i=0}^{\infty} \beta^{i} \ln C_{t+i},
$$

where $0<\beta<1$ is the discount factor. $\mathbb{E}_{t}$ denotes expectations conditioned on information at the start of period $t$. Preferences for households in country $\mathrm{F}$ are similarly defined in terms of foreign consumption, $\hat{C}_{t}$.

Households in our economy can save by holding domestic equity shares, international bonds and equity issued by foreign firms. The budget constraint of the representative $\mathrm{H}$ household can be written as

$$
W_{t+1}=R_{t+1}^{\mathrm{W}}\left(W_{t}-C_{t}\right)
$$

where $W_{t}$ is financial wealth, and $R_{t+1}^{\mathrm{W}}$ is the (gross) return on wealth between period $t$ and $t+1$. This return depends on how the household allocates wealth across the available array of financial 
assets, and on the realized return on those assets. In particular,

$$
R_{t+1}^{\mathrm{W}}=R_{t}+\alpha_{t}^{\mathrm{H}}\left(R_{t+1}^{\mathrm{H}}-R_{t}\right)+\alpha_{t}^{\mathrm{F}}\left(R_{t+1}^{\mathrm{F}}-R_{t}\right)
$$

where $R_{t}$ is the return on bonds and $R_{t+1}^{\mathrm{H}}$ and $R_{t+1}^{\mathrm{F}}$ are the returns on $\mathrm{H}$ and F equity. The fraction of wealth that $\mathrm{H}$ country households hold in $\mathrm{H}$ and F equity are $\alpha_{t}^{\mathrm{H}}$ and $\alpha_{t}^{\mathrm{F}}$ respectively.

The budget constraint for $\mathrm{F}$ households is similarly defined as

$$
\hat{W}_{t+1}=\hat{R}_{t+1}^{\mathrm{W}}\left(\hat{W}_{t}-\hat{C}_{t}\right)
$$

with

$$
\hat{R}_{t+1}^{\mathrm{W}}=R_{t}+\hat{\alpha}_{t}^{\mathrm{H}}\left(R_{t+1}^{\mathrm{H}}-R_{t}\right)+\hat{\alpha}_{t}^{\mathrm{F}}\left(R_{t+1}^{\mathrm{F}}-R_{t}\right),
$$

where $\hat{\alpha}_{t}^{\mathrm{H}}$ and $\hat{\alpha}_{t}^{\mathrm{F}}$ denote the shares of wealth allocated by $\mathrm{F}$ households into $\mathrm{H}$ and $\mathrm{F}$ country equities.

Households in country $\mathrm{H}$ choose how much to consume and how much wealth to allocate into the equity of $\mathrm{H}$ and $\mathrm{F}$ firms to maximize expected utility (4) subject to (5) and (6) given current equity prices and the interest rate on bonds. This problem can be recursively expressed as:

$$
V_{t}\left(W_{t}\right)=\max _{\left\{C_{t}, \alpha_{t}^{\mathrm{H}}, \alpha_{t}^{\mathrm{F}}\right\}}\left\{\ln C_{t}+\beta \mathbb{E}_{t}\left[V_{t+1}\left(R_{t+1}^{\mathrm{W}}\left(W_{t}-C_{t}\right)\right)\right]\right\}
$$

with $C_{t} \geq 0$ and $W_{t}>0$. The optimization problem facing $\mathrm{F}$ households is analogous.

\subsection{Equilibrium}

This section summarizes the conditions characterizing the equilibrium in our model. The first order conditions for the representative $\mathrm{H}$ household's problem in (7) are

$$
\begin{aligned}
1 & =\mathbb{E}_{t}\left[M_{t+1} R_{t+1}^{\mathrm{H}}\right], \\
1 & =\mathbb{E}_{t}\left[M_{t+1} R_{t}\right], \\
1 & =\mathbb{E}_{t}\left[M_{t+1} R_{t+1}^{\mathrm{F}}\right],
\end{aligned}
$$

where $M_{t+1} \equiv \beta\left(\partial U / \partial C_{t+1}\right) /\left(\partial U / \partial C_{t}\right)$ is the discounted intertemporal marginal rate of substitution (IMRS) between the consumption in period $t$ and period $t+1$. The returns on equity issued by $\mathrm{H}$ and $\mathrm{F}$ firms are defined as

$$
R_{t+1}^{\mathrm{H}}=\left(P_{t+1}+D_{t+1}\right) / P_{t} \quad \text { and } \quad R_{t+1}^{\mathrm{F}}=\left(\hat{P}_{t+1}+\hat{D}_{t+1}\right) / \hat{P}_{t} .
$$


With these definitions, the Euler equation in (8a) can be rewritten as $P_{t}=\mathbb{E}_{t}\left[M_{t+1}\left(P_{t+1}+D_{t+1}\right)\right]$. Using this expression to substitute for $P_{t}$ in the $\mathrm{H}$ firm's investment problem 1)-(3) gives the following recursive formulation:

$$
\begin{aligned}
\mathcal{V}\left(K_{t}, Z_{t}\right) & =\max _{I_{t}}\left(D_{t}+P_{t}\right) \\
& =\max _{I_{t}}\left(D_{t}+\beta \mathbb{E}_{t}\left[M_{t+1}\left(D_{t+1}+P_{t+1}\right)\right]\right) \\
& =\max _{I_{t}}\left(Z_{t} K_{t}^{\theta}-I_{t}+\beta \mathbb{E}_{t}\left[M_{t+1} \mathcal{V}\left(K_{t+1}, Z_{t+1}\right)\right]\right)
\end{aligned}
$$

where $\mathcal{V}($.$) denotes the value of the firm. The first order condition associated with this optimization$ problem is

$$
1=\mathbb{E}_{t}\left[M_{t+1} R_{t+1}^{k}\right]
$$

where $R_{t+1}^{k} \equiv \theta Z_{t+1}\left(K_{t+1}\right)^{\theta-1}+(1-\delta)$ is the return on capital. This condition determines the optimal investment of $\mathrm{H}$ firms and thus implicitly identifies the level of dividends in period $t, D_{t}$, via equation (3). The first order conditions for firms in country $\mathrm{F}$ take an analogous form.

It is worth noting that our model has equity home bias built in as firms use the IMRS of domestic agents, (e.g. $M_{t+1}$ in the case of $\mathrm{H}$ firms) to value the dividend steam in (9). Although the array of assets available to households is sufficient for complete risk-sharing in this version of the model, in the two-sector version we present below markets are incomplete. As a result, the IMRS for $\mathrm{H}$ and $\mathrm{F}$ households will differ and households in the two countries will generally prefer different dividend streams. In principle, this formulation of how firms choose investment/dividends can induce home bias in household equity holdings.

Solving for the equilibrium in this economy requires finding equity prices $\left\{P_{t}, \hat{P}_{t}\right\}$, and the interest rate $R_{t}$, such that markets clear when households follow optimal consumption, savings and portfolio strategies, and firms make optimal investment decisions. Under the assumption that bonds are in zero net supply, market clearing in the bond market requires that

$$
0=B_{t}+\hat{B}_{t}
$$

The goods market clears globally. In particular, since H and F firms produce a single good that can be costlessly transported between countries, the market clearing condition is

$$
C_{t}+\hat{C}_{t}=Y_{t}-I_{t}+\hat{Y}_{t}-\hat{I}_{t}=D_{t}+\hat{D}_{t}
$$


The market clearing conditions in the $\mathrm{H}$ and $\mathrm{F}$ equity markets are

$$
1=A_{t}^{\mathrm{H}}+\hat{A}_{t}^{\mathrm{H}} \quad \text { and } \quad 1=A_{t}^{\mathrm{F}}+\hat{A}_{t}^{\mathrm{F}} .
$$

where $A_{t}^{i}$ denotes the number of shares of equity issued by $i=\{\mathrm{H}, \mathrm{F}\}$ firms held by $\mathrm{H}$ households. These share holdings are related to the portfolio shares by the identities, $P_{t} A_{t}^{\mathrm{H}} \equiv \alpha_{t}^{\mathrm{H}}\left(W_{t}-C_{t}\right)$ and $\hat{P}_{t} A_{t}^{\mathrm{F}} \equiv \alpha_{t}^{\mathrm{F}}\left(W_{t}-C_{t}\right)$. The share holdings of F households are $\hat{A}_{t}^{\mathrm{H}}$ and $\hat{A}_{t}^{\mathrm{F}}$ with $P_{t} \hat{A}_{t}^{\mathrm{H}} \equiv \hat{\alpha}_{t}^{\mathrm{H}}\left(\hat{W}_{t}-\hat{C}_{t}\right)$ and $\hat{P}_{t} \hat{A}_{t}^{\mathrm{F}} \equiv \hat{\alpha}_{t}^{\mathrm{F}}\left(\hat{W}_{t}-\hat{C}_{t}\right)$.

\section{Solution Method}

\section{$2.1 \quad$ Overview}

Our solution method extends the perturbation procedure developed by Collard and Juillard (2001), Jin and Judd (2002), and Schmitt-Grohe and Uribe (2004). The extension is necessary to address key features of a general equilibrium model with portfolio choice. As in a standard procedure, the first step is to derive a set of log-linearized equations that characterize the model's equilibrium. The novel aspect of our method is contained in the second step where we use an iterative technique to derive the equilibrium dynamics of the endogenous variables.

The set of linearized equations characterizing the equilibrium of the model can be written in a general form as

$$
\begin{aligned}
0 & =\mathcal{F}\left(Y_{t+1}, Y_{t}, \mathcal{X}_{t+1}, \mathcal{X}_{t}, \mathcal{S}\left(\mathcal{X}_{t}\right)\right) \\
\mathcal{X}_{t+1} & =\mathcal{H}\left(\mathcal{X}_{t}, \mathcal{S}\left(\mathcal{X}_{t}\right)\right)+U_{t+1}
\end{aligned}
$$

where

$$
\begin{aligned}
\mathbb{E}\left(U_{t+1} \mid \mathcal{X}_{t}\right) & =0 \\
\mathbb{E}\left(U_{t+1} U_{t+1}^{\prime} \mid \mathcal{X}_{t}\right) & =\mathcal{S}\left(\mathcal{X}_{t}\right) .
\end{aligned}
$$

Here $\mathcal{X}_{t}$ is a vector of variables that describe the state of the economy at time $t$. In our illustrative model, $\mathcal{X}_{t}$ contains the state of productivity, capital stocks and households' wealth. $Y_{t}$ is a vector of non-predetermined variables at time $t$. It includes consumption, dividends, and asset prices. The function $\mathcal{F}(.$.$) denotes the log-linearized equations characterizing the equilibrium, while \mathcal{H}(.,$. determines how past states affect the current state. $U_{t+1}$ is a vector of shocks driving the equilibrium dynamics of $\mathcal{X}_{t}$. This vector includes both exogenous shocks, like the productivity shocks, and endogenous shocks like the shocks to households' wealth. The shocks have a conditional mean of 
zero and a conditional covariance equal to $\mathcal{S}\left(\mathcal{X}_{t}\right)$, a function of the current state vector $\mathcal{X}_{t}$. Thus our formulation explicitly allows for the possibility that shocks driving the equilibrium dynamics of the state variance are conditionally heteroskedastic. By contrast, standard perturbation methods assume that $U_{t+1}$ follow an i.i.d. process. As we shall see, it is not possible to characterize the equilibrium of a model with portfolio choice and incomplete markets in this way. Conditional heteroskedasticity arises as an inherent feature of the model, and must be accounted for in any solution technique.

Given our formulation in (13) and (14), a solution to the model is characterized by a decision rule for the non-predetermined variables

$$
Y_{t+1}=\mathcal{G}\left(\mathcal{X}_{t+1}, \mathcal{S}\left(\mathcal{X}_{t}\right)\right)
$$

that satisfies the equilibrium conditions in (13):

$$
0=\mathcal{F}\left(\mathcal{G}\left(\mathcal{H}\left(\mathcal{X}_{t}, \mathcal{S}\left(\mathcal{X}_{t}\right)\right)+U_{t+1}, \mathcal{S}\left(\mathcal{X}_{t}\right)\right), \mathcal{G}\left(\mathcal{X}_{t}, \mathcal{S}\left(\mathcal{X}_{t}\right)\right), \mathcal{H}\left(\mathcal{X}_{t}, \mathcal{S}\left(\mathcal{X}_{t}\right)\right)+U_{t+1}, \mathcal{X}_{t}, \mathcal{S}\left(\mathcal{X}_{t}\right)\right)
$$

The iterative procedure we describe below allows us to approximate the $\mathcal{G}(),. \mathcal{H}($.$) and \mathcal{S}($.$) func-$ tions.

\subsection{Log-Linearizations}

To understand why our formulation in (13) and (14) allows for conditional heteroskedasticy in the dynamics of the state vector, we return to the model. In particular, let us focus on the log-linearized equations arising from the households' first order conditions and budget constraint. Hereafter we use lowercase letters to denote log transformation of the corresponding variable, measured as a deviation from its steady state level or initial value.

Following Campbell, Chan and Viceira (2003), hereafter CCV, we use a first-order log-linear approximation to households' budget constraints. In the case of $\mathrm{H}$ households it is given by

$$
\begin{aligned}
\Delta w_{t+1} & =\ln \left(1-C_{t} / W_{t}\right)+r_{t+1}^{\mathrm{W}}, \\
& =\kappa-\frac{\mu}{1-\mu}\left(c_{t}-w_{t}\right)+r_{t+1}^{\mathrm{W}},
\end{aligned}
$$

where $\mu$ is the steady state consumption wealth ratio and $\kappa \equiv \ln (1-\mu)$. In our model, households have log preferences so the optimal consumption/wealth ratio is a constant equal to $1-\beta$. In this case $c_{t}-w_{t}=0$ and $\kappa=\ln \beta . r_{t+1}^{\mathrm{W}}$ is the log return on optimally invested wealth which CCV 
approximate as

$$
r_{t+1}^{\mathrm{W}}=r_{t}+\boldsymbol{\alpha}_{t}^{\prime} e r_{t+1}+\frac{1}{2} \boldsymbol{\alpha}_{t}^{\prime}\left(\operatorname{diag}\left(\Theta_{t}\right)-\Theta_{t} \boldsymbol{\alpha}_{t}\right)
$$

where $\boldsymbol{\alpha}_{t}^{\prime} \equiv\left[\begin{array}{ll}\alpha_{t}^{\mathrm{H}} & \alpha_{t}^{\mathrm{F}}\end{array}\right]$ is the vector of portfolio shares, $e r_{t+1}^{\prime} \equiv\left[\begin{array}{ll}r_{t+1}^{\mathrm{H}}-r_{t} & r_{t+1}^{\mathrm{F}}-r_{t}\end{array}\right]$ is a vector of excess equity returns, and $\Theta_{t}$ is the conditional covariance of $e r_{t+1}$. The approximation error associated with this expression disappears in the limit where returns follow continuous-time diffusion processes.

Next, we turn to the first-order conditions in (8). Using the standard log-normal approximation, we obtain

$$
\begin{aligned}
\mathbb{E}_{t} r_{t+1}^{\chi}-r_{t}+\frac{1}{2} \mathbb{V}_{t}\left(r_{t+1}^{\chi}\right) & =-\mathbb{C V}_{t}\left(m_{t+1}, r_{t+1}^{\chi}\right) \\
r_{t} & =-\mathbb{E}_{t} m_{t+1}-\frac{1}{2} \mathbb{V}_{t}\left(m_{t+1}\right),
\end{aligned}
$$

where $r_{t+1}^{\chi}$ is the $\log$ return for equity $\chi=\{\mathrm{H}, \mathrm{F}\}$, and $m_{t+1} \equiv \ln M_{t+1}$ is the $\log \operatorname{IMRS}$. $\mathbb{V}_{t}($.$) and$ $\mathbb{C V}_{t}(.,$.$) denote the variance and covariance conditioned on period- t$ information. With log utility $m_{t+1}=\ln \beta-\Delta c_{t+1}=\ln \beta-\Delta w_{t+1}$, so (18a) can be rewritten as

$$
\mathbb{E}_{t} e r_{t+1}=\Theta_{t} \boldsymbol{\alpha}_{t}-\frac{1}{2} \operatorname{diag}\left(\Theta_{t}\right)
$$

Combining this expression with (16) and (17) gives

$$
\Delta w_{t+1}=\kappa-\frac{1-\mu}{\mu}\left(c_{t}-w_{t}\right)+r_{t}+\frac{1}{2} \boldsymbol{\alpha}_{t}^{\prime} \Theta_{t} \boldsymbol{\alpha}_{t}+\boldsymbol{\alpha}_{t}^{\prime}\left(e r_{t+1}-\mathbb{E}_{t} e r_{t+1}\right)
$$

Equation (20) provides us with a log-linear version of the $\mathrm{H}$ household's budget constraint. It shows that the growth in household wealth between $t$ and $t+1$ depends upon the consumption/wealth ratio in period $t$ (a constant in the case of $\log$ utility), the period- $t$ risk free rate, $r_{t}$, portfolio shares, $\boldsymbol{\alpha}_{t}$, the variance-covariance matrix of excess returns, $\Theta_{t}$, and the unexpected return on assets held between $t$ and $t+1, \boldsymbol{\alpha}_{t}^{\prime}\left(e r_{t+1}-\mathbb{E}_{t} e r_{t+1}\right)$. Notice that the susceptibility of wealth in $t+1$ to unexpected returns depends on the period- $t$ portfolio choices. Consequently, the volatility of wealth depends endogenously on the portfolio choices made by households and the equilibrium behavior of returns. In an equilibrium where returns have an i.i.d. distribution, $\boldsymbol{\alpha}_{t}$ will be constant, and wealth will be conditionally homoskedastic. Of course in a general equilibrium setting the properties of returns are themselves determined endogenously, so there is no guarantee that optimally chosen portfolio shares or the second moments of returns will be constant. Indeed, in general we should expect the equilibrium process for wealth to display conditional heteroskedasticity. It is worth emphasizing that heteroskedasticity does not arise because we are 
dealing with a log-linearized version of the household's budget constraint. It is an inherent feature of the household's budget constraint because portfolio choices affect the susceptibility of future wealth to the unexpected returns on individual assets (see equations 5 and 6 above). The log-linear approximation in (20) simply illustrates the point in a particularly clear way.

Standard perturbation methods can still be used to solve models where the equilibrium dynamics of the wealth are conditionally heteroskedastic. If the equilibrium dynamics of the model can be described in terms of the state variable $\mathcal{X}_{t}$ that excludes wealth, it may be possible to retain the i.i.d. assumption on the $U_{t}$ shocks. This is possible in models with portfolio choice when the array of assets allows for perfect risk-sharing among agents, so that markets are complete. When markets are incomplete, by contrast, it is not possible to characterize the equilibrium dynamics of the economy without including household wealth in the state vector $\mathcal{X}_{t}$. As a consequence, in this setting it is necessary to allow for conditional heteroskedasticity in the dynamics of the state variable as our formulation in (13) and (14) does.

Equation (19) implicitly identifies the optimal choice of the H households' portfolio shares, $\boldsymbol{\alpha}_{t}$. This equation was derived from the household's first-order conditions under the assumption that the joint conditional distribution of log returns is approximately normal. Notice that the approximation method does not require an assumption about the portfolio shares chosen in the steady state. By contrast, standard perturbation methods consider Taylor series approximations to the model's equilibrium conditions with respect to decision variables around the value they take in the nonstochastic steady state. As Judd and Guu (2000) point out, this method is inapplicable when the steady-state value of the decision variable is indeterminate. This is an important observation when solving a model involving portfolio choice. In the non-stochastic steady state, assets are perfect substitutes in household portfolios because returns are identical, so the optimal choice of portfolio is indeterminate.

While the steady state portfolio shares are absent from equation (19), the problem of indeterminacy still arises in our model. In particular, we have to take a stand on the steady state distribution of asset holdings when log-linearizing the market clearing conditions: Consider, for example, the market clearing condition for $\mathrm{H}$ equity in (12). Combining this condition with the portfolio share definitions, and the fact that the consumption/wealth ratio for all households is equal to $1-\beta$, we obtain

$$
\frac{P_{t}}{\beta W_{t}}=\alpha_{t}^{\mathrm{H}}+\hat{\alpha}_{t}^{\mathrm{H}} \frac{\hat{W}_{t}}{W_{t}} .
$$

We consider a second-order Taylor series approximation to this expression around the steady state values for $P_{t} / \beta W_{t}$ and $\hat{W}_{t} / W_{t}$. To pin down these values, we parameterize the value of $\hat{W} / W$ and 
then work out its implications for the value of $P / \beta W .{ }^{4}$ This is particularly simple in the case where wealth is equally distributed (i.e. $\hat{W} / W=1$ ). Here symmetry and market clearing in the goods market requires that $D=C=(1-\beta) W$. It follows that $P / \beta W=[(1-\beta) / \beta](P / D)=1$ because the Euler equation for stock returns implies that the steady state value of $P / D$ equals $\beta /(1-\beta)$. In this case, the second-order log-approximation embedding goods market clearing becomes

$$
1+p_{t}-w_{t}+\frac{1}{2}\left(p_{t}-w_{t}\right)^{2}=\alpha_{t}^{\mathrm{H}}+\hat{\alpha}_{t}^{\mathrm{H}}\left(1+\hat{w}_{t}-w_{t}+\frac{1}{2}\left(\hat{w}_{t}-w_{t}\right)^{2}\right) .
$$

Log-linear approximations implied by the other market clearing conditions are similarly obtained. Specifically, when wealth is equally distributed, market clearing in F equity, bonds and goods imply that

$$
\begin{aligned}
1+\hat{p}_{t}-\hat{w}_{t}+\frac{1}{2}\left(\hat{p}_{t}-\hat{w}_{t}\right)^{2} & =\hat{\alpha}_{t}^{\mathrm{F}}+\alpha_{t}^{\mathrm{F}}\left(1+w_{t}-\hat{w}_{t}+\frac{1}{2}\left(w_{t}-\hat{w}_{t}\right)^{2}\right) \\
p_{t}+\hat{p}_{t} & =d_{t}+\hat{d}_{t} \\
c_{t}+\hat{c}_{t} & =d_{t}+\hat{d}_{t}
\end{aligned}
$$

This approach to the indeterminacy problem also has another important advantage. The presence of wealth as a state variable introduces a nonstationary unit root component into the $\mathcal{X}_{t}$ process because shocks to returns will generally have permanent effects on wealth. ${ }^{5}$ As we show below, our procedure accommodates the presence of a unit root by characterizing the equilibrium dynamics of the model in a neighborhood of the initial state, $\mathcal{X}_{0}$. To study the equilibrium properties of the model we must therefore specify the elements of $\mathcal{X}_{0}$. Thus, specifying the initial distribution of wealth not only provides a way to resolve indeterminacy concerning portfolio shares in the nonstochastic steady state, it also allows us to analyze the equilibrium dynamics of a model that is inherently nonstationary.

The remaining equations characterizing the model's equilibrium are log-linearized in a standard way. Optimal investment by $\mathrm{H}$ and $\mathrm{F}$ firms requires that

$$
\begin{aligned}
& \mathbb{E}_{t} r_{t+1}^{k}-r_{t}+\frac{1}{2} \mathbb{V}_{t}\left(r_{t+1}^{k}\right)=\mathbb{C} \mathbb{V}_{t}\left(r_{t+1}^{k}, \Delta w_{t+1}\right) \\
& \mathbb{E}_{t} \hat{r}_{t+1}^{k}-r_{t}+\frac{1}{2} \mathbb{V}_{t}\left(\hat{r}_{t+1}^{k}\right)=\mathbb{C} \mathbb{V}_{t}\left(\hat{r}_{t+1}^{k}, \Delta \hat{w}_{t+1}\right)
\end{aligned}
$$

\footnotetext{
${ }^{4}$ Our approach of parametrizing the initial wealth distribution across agents is an alternative to the Judd and Guu (2000) bifurcation procedure for dealing with portfolio indeterminacy.

${ }^{5}$ For example, when households have log preferences the first two terms on the right in (20) are constant. Under these circumstances, a positive unexpected return will permenantly raise wealth unless the household finds it optimal to adjust their future portfolio shares so that $\boldsymbol{\alpha}_{t+i}^{\prime} \Theta_{t+i} \boldsymbol{\alpha}_{t+i}$ falls and/or $r_{t+i}$ falls by a compensating amount.
} 
where $r_{t+1}^{k}$ and $\hat{r}_{t+1}^{k}$ are the log returns on capital approximated by

$$
r_{t+1}^{k} \cong \psi z_{t+1}-(1-\theta) \psi k_{t+1} \quad \text { and } \quad \hat{r}_{t+1}^{k} \cong \psi \hat{z}_{t+1}-(1-\theta) \psi \hat{k}_{t+1},
$$

with $\psi \equiv 1-\beta(1-\delta)<1$. The dynamics of the $\mathrm{H}$ and $\mathrm{F}$ capital stock are approximated by

$$
k_{t+1} \cong \frac{1}{\beta} k_{t}+\frac{\psi}{\beta \theta} z_{t}-\left(\frac{\psi}{\theta \beta}-\delta\right) d_{t} \quad \text { and } \quad \hat{k}_{t+1} \cong \frac{1}{\beta} \hat{k}_{t}+\frac{\psi}{\beta \theta} \hat{z}_{t}-\left(\frac{\psi}{\theta \beta}-\delta\right) \hat{d}_{t} .
$$

Finally, we turn to the relationship between the price of equity, dividends and returns. As in Campbell and Shiller (1989), we relate the log return on equity to log dividends and the log price of equity by

$$
r_{t+1}^{\mathrm{H}}=\rho p_{t+1}+(1-\rho) d_{t+1}-p_{t} \quad \text { and } \quad r_{t+1}^{\mathrm{F}}=\hat{\rho} \hat{p}_{t+1}+(1-\hat{\rho}) \hat{d}_{t+1}-\hat{p}_{t},
$$

with $\rho \equiv 1 /(1+\exp (\overline{d-p}))$ and $\hat{\rho} \equiv 1 /(1+\exp (\overline{\hat{d}-\hat{p}}))$ where $\overline{d-p}$ and $\overline{\hat{d}-\hat{p}}$ are the average $\log$ dividend-price ratios in the $\mathrm{H}$ and $\mathrm{F}$ countries. In the non-stochastic steady state $\rho=\hat{\rho}=\beta$. Making this substitution, iterating forward with $\lim _{j \rightarrow \infty} \beta^{j} p_{t+j}^{\chi}=0$, and taking conditional expectations, we obtain

$$
\begin{aligned}
& p_{t}=\sum_{i=0}^{\infty} \beta^{i}\left\{(1-\beta) \mathbb{E}_{t} d_{t+1+i}-\mathbb{E}_{t} r_{t+1+i}^{\mathrm{H}}\right\} \\
& \hat{p}_{t}=\sum_{i=0}^{\infty} \beta^{i}\left\{(1-\beta) \mathbb{E}_{t} \hat{d}_{t+1+i}-\mathbb{E}_{t} r_{t+1+i}^{\mathrm{F}}\right\}
\end{aligned}
$$

These approximations show how log equity prices are related to expected future dividends and returns.

\subsection{State Variables Dynamics}

The key step in our solution procedure is deriving a general yet tractable set of equations that describe the equilibrium dynamics of the state variables. One problem we immediately face in this regard is the dimensionality of the state vector. As we noted above, the distribution of wealth plays an integral role in determining equilibrium prices and returns when markets are incomplete, so household wealth needs to be included in the state vector. In models with a continuum of heterogenous households it is obviously impossible to track the wealth of individuals, so moments of the wealth distribution need to be included in the state vector. The question of how many 
moments to include is not easily answered.

Dimensionality is still a problem when heterogeneity across households is limited. In our model there are only two types of households, so it suffices to keep track of $\mathrm{H}$ and F households' wealth. The dimensionality problem occurs under these circumstances because uncertainty enters multiplicatively into the dynamics of wealth. (Recall that portfolio shares determine the susceptibility of wealth to unexpected return shocks.) If wealth is part of the state vector, $\mathcal{X}_{t}$, and both portfolio shares and realized returns depend on $\mathcal{X}_{t}$, the level of wealth will depend on the elements in $\mathcal{X}_{t} \mathcal{X}_{t}^{\prime}$. This means that the equilibrium dynamics of wealth will in general depend on the behavior of the levels, squares and cross-products of the individual state variables. This dependence between the lower and higher moments of the state variables remains even after log-linearization. In equation (20) we see that $\mathrm{H}$ household wealth depends on the quadratic form for portfolio shares, which are themselves functions of the state vector, including wealth. As a result, the state vector needs to be expanded to include squares and cross-products. Of course a similar logic applies to the equilibrium behavior of squares and cross-products involving wealth. So by induction, a complete characterization of the equilibrium wealth dynamics could easily require an infinite number of elements in $\mathcal{X}$. Our solution procedure uses a finite subset of state variables $X \subset \mathcal{X}$ that provides a good approximation to the equilibrium dynamics.

We will use the model presented in Section 1 to illustrate our procedure. Let $x_{t} \equiv\left[z_{t}, k_{t}, \hat{k}_{t}, w_{t}, \hat{w}_{t}\right]^{\prime}$ where $k_{t} \equiv \ln \left(K_{t} / K\right), \hat{k}_{t} \equiv \ln \left(\hat{K}_{t} / K\right), w_{t} \equiv \ln \left(W_{t} / W_{0}\right)$ and $\hat{w}_{t} \equiv \ln \left(\hat{W}_{t} / \hat{W}_{0}\right)$. More generally, $x_{t}$ will be an $n \times 1$ vector that contains the variables that make up the state vector. We will approximate the equilibrium dynamics of the model with the vector

$$
X_{t}=\left[\begin{array}{c}
1 \\
x_{t} \\
\tilde{x}_{t}
\end{array}\right],
$$

where $\tilde{x}_{t} \equiv \operatorname{vec}\left(x_{t} x_{t}^{\prime}\right)$. The vector $X_{t}$ contains $k=1+n+n^{2}$ elements.

To determine the dynamics of $X_{t}$, we first conjecture that $x_{t}$ follows

$$
x_{t+1}=\Phi_{0}+\left(I-\Phi_{1}\right) x_{t}+\Phi_{2} \tilde{x}_{t}+\varepsilon_{t+1},
$$

where $\Phi_{0}$ is the $n \times 1$ vector of constants, $\Phi_{1}$ is the $n \times n$ matrix of autoregressive coefficients and $\Phi_{2}$ is the $n \times n^{2}$ matrix of coefficients on the second-order terms. $\varepsilon_{t+1}$ is a vector of innovations 
with zero conditional mean, and conditional covariance that is a function of $X_{t}$ :

$$
\begin{aligned}
\mathbb{E}\left(\varepsilon_{t+1} \mid x_{t}\right) & =0 \\
\mathbb{E}\left(\varepsilon_{t+1} \varepsilon_{t+1}^{\prime} \mid x_{t}\right) & =\Omega\left(X_{t}\right)=\Omega_{0}+\Omega_{1} x_{t} x_{t}^{\prime} \Omega_{1}^{\prime} .
\end{aligned}
$$

Below we shall use the vectorized conditional variance which we write as

$$
\operatorname{vec}\left(\Omega\left(X_{t}\right)\right)=\left[\begin{array}{ccc}
\Sigma_{0} & 0 & \Sigma_{1}
\end{array}\right]\left[\begin{array}{c}
1 \\
x_{t} \\
\tilde{x}_{t}
\end{array}\right]=\Sigma X_{t}
$$

The next step is to derive an equation describing the dynamics of $\tilde{x}_{t}$ consistent with (27) and (28). For this purpose we consider the continuous time analogue to (27) and derive the dynamics of $\tilde{x}_{t+1}$ via Ito's lemma. As the Appendix shows, the resulting process can be approximated in discrete time by

$$
\tilde{x}_{t+1}=\frac{1}{2} D \Sigma_{0}+\left(\Phi_{0} \otimes I\right)+\left(I \otimes \Phi_{0}\right) x_{t}+\left(I-\left(\Phi_{1} \otimes I\right)-\left(I \otimes \Phi_{1}\right)+\frac{1}{2} D \Sigma_{1}\right) \tilde{x}_{t}+\tilde{\varepsilon}_{t+1}
$$

where

$$
\begin{gathered}
\tilde{\varepsilon}_{t+1}=\left[\left(I \otimes x_{t}\right)+\left(x_{t} \otimes I\right)\right] \varepsilon_{t+1} \\
D=\left[U\left(\frac{\partial x}{\partial x^{\prime}} \otimes I\right)+\left(\frac{\partial x}{\partial x^{\prime}} \otimes I\right)\right], \quad \text { and } \quad U=\sum_{r} \sum_{s} E_{r s} \otimes E_{r, s}^{\prime} .
\end{gathered}
$$

$E_{r, s}$ is the elementary matrix which has a unity at the $(r, s)^{t h}$ position and zero elsewhere. Equation (29) approximates the dynamics of $\tilde{x}_{t+1}$ because it ignores the role played by cubic and higher order terms involving the elements of $x_{t}$. In this sense, (29) represents a second-order approximation to the dynamics of the second-order terms in the state vector. ${ }^{6}$ Notice that the variance of $\varepsilon_{t+1}$ affects the dynamics of $\tilde{x}_{t+1}$ via the $D$ matrix and that $\tilde{\varepsilon}_{t+1}$ will generally be conditionally heteroskedastic.

We can now combine (27) and (29) into a single equation:

$$
\left[\begin{array}{c}
1 \\
x_{t+1} \\
\tilde{x}_{t+1}
\end{array}\right]=\left[\begin{array}{ccc}
1 & 0 & 0 \\
\Phi_{0} & I-\Phi_{1} & \Phi_{2} \\
\frac{1}{2} D \Sigma_{0} & \left(\Phi_{0} \otimes I\right)+\left(I \otimes \Phi_{0}\right) & I-\left(\Phi_{1} \otimes I\right) \\
-\left(I \otimes \Phi_{1}\right)+\frac{1}{2} D \Sigma_{1}
\end{array}\right]\left[\begin{array}{c}
1 \\
x_{t} \\
\tilde{x}_{t}
\end{array}\right]+\left[\begin{array}{c}
0 \\
\varepsilon_{t+1} \\
\tilde{\varepsilon}_{t+1}
\end{array}\right],
$$

\footnotetext{
${ }^{6}$ One way to check the accuracy of this approximation is to derive a generalization of (29) involving third-order terms and then compute the contribution of these terms to the dynamics of $x_{t}$ and $\tilde{x}_{t}$. Since the elements of $x_{t}$ are measured in terms of percentage deviations from steady state or initial values, third order terms are unlikely to be significant. Nevertheless, as we note below, we are cognizant of the approximation error in (29) when examining the "solution" to a model.
} 
or more compactly

$$
X_{t+1}=\mathbb{A} X_{t}+U_{t+1}
$$

with $\mathbb{E}\left(U_{t+1} \mid X_{t}\right)=0$. We also need to determine the conditional covariance of the $U_{t+1}$ vector. In the Appendix we show that

$$
\mathbb{E}\left(U_{t+1} U_{t+1}^{\prime} \mid X_{t}\right) \equiv \mathcal{S}\left(X_{t}\right)=\left(\begin{array}{ccc}
0 & 0 & 0 \\
0 & \Omega\left(X_{t}\right) & \Gamma\left(X_{t}\right) \\
0 & \Gamma\left(X_{t}\right)^{\prime} & \Psi\left(X_{t}\right)
\end{array}\right)
$$

where

$$
\begin{aligned}
\operatorname{vec}\left(\Gamma\left(X_{t}\right)\right) & =\Gamma_{0}+\Gamma_{1} x_{t}+\Gamma_{2} \tilde{x}_{t}, \\
\operatorname{vec}\left(\Gamma\left(X_{t}\right)^{\prime}\right) & =\Lambda_{0}+\Lambda_{1} x_{t}+\Lambda_{2} \tilde{x}_{t}, \\
\operatorname{vec}\left(\Psi\left(X_{t}\right)\right) & =\Psi_{0}+\Psi_{1} x_{t}+\Psi_{2} \tilde{x}_{t} .
\end{aligned}
$$

The $\Gamma_{i}, \Lambda_{i}$ and $\Psi_{i}$ matrices are complicated functions of the parameters in (27) and (28); their precise form is shown in the Appendix.

To this point we have shown how to approximate the dynamics of $X_{t}$ given a conjecture concerning $\Phi_{0}, \Phi_{1}, \Phi_{2}, \Sigma_{0}$ and $\Sigma_{1}$. We now turn to the issue of how these matrices are determined. For this purpose we make use of two further results. Let $a_{t}$ and $b_{t}$ be two generic endogenous variables related to the state vector by $a_{t}=\pi_{a} X_{t}$ and $b_{t}=\pi_{b} X_{t}$, where $\pi_{a}$ and $\pi_{b}$ are $1 \times k$ vectors. Our second-order approximation for the dynamics of $X_{t}$ implies that

$$
\mathbb{C V}_{t}\left(a_{t+1}, b_{t+1}\right)=\mathcal{A}\left(\pi_{a}, \pi_{b}\right) X_{t}
$$

and

$$
a_{t} b_{t}=\mathcal{B}\left(\pi_{a}, \pi_{b}\right) X_{t}
$$

$\mathcal{A}(.,$.$) and \mathcal{B}(.,$.$) are 1 \times k$ vectors with elements that depend on $\pi_{a}, \pi_{b}$ and the parameters of the $X_{t}$ process. The precise form of these vectors is also shown in the Appendix.

To see how these results are used, we return to the model. The dynamics of the state vector depend upon households' portfolio choices, $\left\{\alpha_{t}^{\mathrm{H}}, \alpha_{t}^{\mathrm{F}}, \hat{\alpha}_{t}^{\mathrm{H}}, \hat{\alpha}_{t}^{\mathrm{F}}\right\}$, firms' dividend choices, $\left\{d_{t}, \hat{d}_{t}\right\}$, equilibrium equity prices, $\left\{p_{t}, \hat{p}_{t}\right\}$, and the risk free rate, $r_{t}$. Let us assume, for the present, that each of these non-predetermined variables is linearly related to the state. (We shall verify that this is indeed the case below.) In particular, let $\pi_{i}$ be the $1 \times k$ row vector that relates variable $i$ to the state $X_{t}$ and let $h_{i}$ be the $1 \times k$ vector that selects the $i^{\text {th }}$ element out of $X_{t}$. We can now easily 
derive the restrictions on the dynamics of productivity, capital and wealth.

Recall that the first two rows of $x_{t}$ comprise the vector of productivities that follow an exogenous $\operatorname{AR}(1)$ process. The corresponding elements of $\Phi_{0}, \Phi_{1}, \Phi_{2}, \Sigma_{0}$ and $\Sigma_{1}$ are therefore entirely determined by the parameters of this process.

The next elements in $x_{t}$ are the log capital stocks. If equilibrium dividends satisfy $d_{t}=\pi_{d} X_{t}$ and $\hat{d}_{t}=\pi_{\hat{d}} X_{t}$, we can rewrite the log-linearized dynamics for $k_{t}$ and $\hat{k}_{t}$ shown in (24) as

$$
\begin{aligned}
& h_{k} X_{t+1}=\left(\frac{1}{\beta} h_{k}+\frac{\psi}{\beta \theta} h_{z}-\left(\frac{\psi}{\theta \beta}-\delta\right) \pi_{d}\right) X_{t} \\
& h_{\hat{k}} X_{t+1}=\left(\frac{1}{\beta} h_{\hat{k}}+\frac{\psi}{\beta \theta} h_{\hat{z}}-\left(\frac{\psi}{\theta \beta}-\delta\right) \pi_{\hat{d}}\right) X_{t} .
\end{aligned}
$$

Notice that these equations must hold for all realizations of $X_{t}$. So substituting for $X_{t+1}$ with (30) and equating coefficients we obtain

$$
h_{k} \mathbb{A}=\frac{1}{\beta} h_{k}+\frac{\psi}{\beta \theta} h_{z}-\left(\frac{\psi}{\theta \beta}-\delta\right) \pi_{d} \quad \text { and } \quad h_{\hat{k}} \mathbb{A}=\frac{1}{\beta} h_{\hat{k}}+\frac{\psi}{\beta \theta} h_{\hat{z}}-\left(\frac{\psi}{\theta \beta}-\delta\right) \pi_{\hat{d}}
$$

These equations place restrictions on the elements of $\Phi_{0}, \Phi_{1}$, and $\Phi_{2}$. Furthermore, because $k_{t+1}$ and $\hat{k}_{t+1}$ are solely functions of the period $-t$ state, the corresponding element rows and columns of $\mathbb{E}\left(\varepsilon_{t+1} \varepsilon_{t+1}^{\prime} \mid X_{t}\right) \equiv \Omega\left(X_{t}\right)$ are vectors of zeros. This observation puts restrictions on the elements of $\Sigma_{0}$ and $\Sigma_{1}$.

Deriving the equilibrium restrictions on the dynamics of wealth is a little more complicated and requires the use of $\mathrm{R} 1$ and $\mathrm{R} 2$. Our starting point is the approximation for log equity returns in (25) which we now write in terms of the state vector:

$$
r_{t+1}^{\mathrm{H}}=\pi_{\mathrm{H}} X_{t+1}-\pi_{p} X_{t} \quad \text { and } \quad r_{t+1}^{\mathrm{F}}=\pi_{\mathrm{F}} X_{t+1}-\pi_{\hat{p}} X_{t}
$$

where $\pi_{\mathrm{H}} \equiv \beta \pi_{p}+(1-\beta) \pi_{d}$ and $\pi_{\mathrm{F}} \equiv \beta \pi_{\hat{p}}+(1-\beta) \pi_{\hat{d}}$. Notice that unexpected log returns are $r_{t+1}^{\chi}-\mathbb{E}_{t} r_{t+1}^{\chi}=\pi_{\chi}\left(X_{t+1}-\mathbb{E}_{t} X_{t+1}\right)$ for $\chi=\{\mathrm{H}, \mathrm{F}\}$, so applying R1 we obtain

$$
\mathbb{V}_{t}\left(e r_{t+1}\right) \equiv \Theta_{t}=\left[\begin{array}{cc}
\mathcal{A}\left(\pi_{\mathrm{H}}, \pi_{\mathrm{H}}\right) X_{t} & \mathcal{A}\left(\pi_{\mathrm{H}}, \pi_{\mathrm{F}}\right) X_{t} \\
\mathcal{A}\left(\pi_{\mathrm{H}}, \pi_{\mathrm{F}}\right) X_{t} & \mathcal{A}\left(\pi_{\mathrm{F}}, \pi_{\mathrm{F}}\right) X_{t}
\end{array}\right]
$$

Now recall that our log-linearized version of the H household budget constraint contains a quadratic function of the portfolio shares and $\Theta_{t}$. To evaluate this component, let us assume that the portfolio 
shares satisfy $\alpha_{t}^{\mathrm{H}}=\pi_{\alpha}^{\mathrm{H}} X_{t}$ and $\alpha_{t}^{\mathrm{F}}=\pi_{\alpha}^{\mathrm{F}} X_{t}$, so that

$$
\boldsymbol{\alpha}_{t}^{\prime} \Theta_{t} \boldsymbol{\alpha}_{t}=\left[\begin{array}{ll}
\pi_{\alpha}^{\mathrm{H}} X_{t} & \pi_{\alpha}^{\mathrm{F}} X_{t}
\end{array}\right]\left[\begin{array}{cc}
\mathcal{A}\left(\pi_{\mathrm{H}}, \pi_{\mathrm{H}}\right) X_{t} & \mathcal{A}\left(\pi_{\mathrm{H}}, \pi_{\mathrm{F}}\right) X_{t} \\
\mathcal{A}\left(\pi_{\mathrm{H}}, \pi_{\mathrm{F}}\right) X_{t} & \mathcal{A}\left(\pi_{\mathrm{F}}, \pi_{\mathrm{F}}\right) X_{t}
\end{array}\right]\left[\begin{array}{c}
\pi_{\alpha}^{\mathrm{H}} X_{t} \\
\pi_{\alpha}^{\mathrm{F}} X_{t}
\end{array}\right]
$$

Applying $\mathrm{R} 2$ to the right hand side gives

$$
\begin{aligned}
\boldsymbol{\alpha}_{t}^{\prime} \Theta_{t} \boldsymbol{\alpha}_{t}= & \mathcal{B}\left(\pi_{\alpha}^{\mathrm{H}}, \mathcal{B}\left(\mathcal{A}\left(\pi_{\mathrm{H}}, \pi_{\mathrm{H}}\right), \pi_{\alpha}^{\mathrm{H}}\right)+\mathcal{B}\left(\mathcal{A}\left(\pi_{\mathrm{H}}, \pi_{\mathrm{F}}\right), \pi_{\alpha}^{\mathrm{F}}\right)\right) X_{t} \\
& +\mathcal{B}\left(\pi_{\alpha}^{\mathrm{F}}, \mathcal{B}\left(\mathcal{A}\left(\pi_{\mathrm{H}}, \pi_{\mathrm{F}}\right), \pi_{\alpha}^{\mathrm{H}}\right)+\mathcal{B}\left(\mathcal{A}\left(\pi_{\mathrm{F}}, \pi_{\mathrm{F}}\right), \pi_{\alpha}^{\mathrm{F}}\right)\right) X_{t} \\
= & \Lambda X_{t} .
\end{aligned}
$$

According to (20), $\mathbb{E}_{t} w_{t+1}=w_{t}+\ln \beta+r_{t}+\frac{1}{2} \boldsymbol{\alpha}_{t}^{\prime} \Theta_{t} \boldsymbol{\alpha}_{t}$, while the dynamics of the state vector imply that $\mathbb{E}_{t} w_{t+1}=h_{w} \mathbb{A} X_{t}$. Equating these moments for all possible values of $X_{t}$ requires that

$$
h_{w} \mathbb{A}=h_{w}+\ln \beta h_{1}+\pi_{r}+\frac{1}{2} \Lambda
$$

This expression provides us with another set of restrictions on the elements of $\Phi_{0}, \Phi_{1}$, and $\Phi_{2}$.

The model also places restrictions on the second moments of wealth. To derive these restrictions we first note that for any variable $a_{t}=\pi_{a} X_{t}$,

$$
\mathbb{C} \mathbb{V}_{t}\left(w_{t+1}, a_{t+1}\right)=\alpha_{t}^{\mathrm{H}} \mathbb{C} \mathbb{V}_{t}\left(r_{t+1}^{\mathrm{H}}, a_{t+1}\right)+\alpha_{t}^{\mathrm{F}} \mathbb{C} \mathbb{V}_{t}\left(r_{t+1}^{\mathrm{F}}, a_{t+1}\right)
$$

Applying R1 and R2 to the right hand side, gives

$$
\begin{aligned}
\mathbb{C V}_{t}\left(w_{t+1}, a_{t+1}\right) & =\pi_{\alpha}^{\mathrm{H}} X_{t} \mathcal{A}\left(\pi_{\mathrm{H}}, \pi_{a}\right) X_{t}+\pi_{\alpha}^{\mathrm{F}} X_{t} \mathcal{A}\left(\pi_{\mathrm{F}}, \pi_{a}\right) X_{t} \\
& =\left(\mathcal{B}\left(\pi_{\alpha}^{\mathrm{H}}, \mathcal{A}\left(\pi_{\mathrm{H}}, \pi_{a}\right)\right)+\mathcal{B}\left(\pi_{\alpha}^{\mathrm{F}}, \mathcal{A}\left(\pi_{\mathrm{F}}, \pi_{a}\right)\right)\right) X_{t} .
\end{aligned}
$$

Our conjecture for the conditional covariance of $x_{t}$ in (28) implies that the second moments of wealth depend only on the constant and second order terms in $X_{t}$. This conjecture requires that

$$
h_{a}\left[\begin{array}{ccc}
\Sigma_{0} & 0 & \Sigma_{1}
\end{array}\right]=\mathcal{B}\left(\pi_{\alpha}^{\mathrm{H}}, \mathcal{A}\left(\pi_{\mathrm{H}}, \pi_{a}\right)\right)+\mathcal{B}\left(\pi_{\alpha}^{\mathrm{F}}, \mathcal{A}\left(\pi_{\mathrm{F}}, \pi_{a}\right)\right)
$$

where $h_{a} \operatorname{vec}\left(\Omega\left(X_{t}\right)\right)=\mathbb{C V}_{t}\left(w_{t+1}, a_{t+1}\right)$. For $a$ we use the elements of $x_{t} \equiv\left[z_{t}, k_{t}, \hat{k}_{t}, w_{t}, \hat{w}_{t}\right]^{\prime}$. An analogous set of restrictions apply to the dynamics of $\mathrm{F}$ household wealth. 


\subsection{Non-Predetermined Variable Dynamics}

To this point we have shown how the equilibrium conditions of the model impose restrictions on the dynamics of the state variables under the assumption that the vector of non-predetermined variables $Y_{t}$ (i.e., $\alpha_{t}^{\mathrm{H}}, \alpha_{t}^{\mathrm{F}}, \hat{\alpha}_{t}^{\mathrm{H}}, \hat{\alpha}_{t}^{\mathrm{F}} d_{t}, \hat{d}_{t}, p_{t}, \hat{p}_{t}$ and $r_{t}$ ) satisfy

$$
Y_{t}=\Pi X_{t}
$$

for some matrix $\Pi$ with rows $\pi_{i}$. We now turn to the question of how the elements of $\Pi$ are determined from the equilibrium conditions and the dynamics of the state vector.

We begin with the restrictions on $\mathrm{H}$ equity prices. In particular, our aim is to derive a set of restrictions that will enable us to identify the elements of $\pi_{p}$ where $p_{t}=\pi_{p} X_{t}$ in equilibrium. Our derivation starts with expected returns. Specifically, we note from the log-linearized first order conditions in (18a) that

$$
\begin{aligned}
\mathbb{E}_{t} r_{t+1}^{\mathrm{H}} & =r_{t}+\mathbb{C} \mathbb{V}_{t}\left(w_{t+1}, r_{t+1}^{\mathrm{H}}\right)-\frac{1}{2} \mathbb{V}_{t}\left(r_{t+1}^{\mathrm{H}}\right), \\
& =r_{t}+\left(\mathcal{B}\left(\pi_{\alpha}^{\mathrm{H}}, \mathcal{A}\left(\pi_{\mathrm{H}}, \pi_{\mathrm{H}}\right)\right)+\mathcal{B}\left(\pi_{\alpha}^{\mathrm{F}}, \mathcal{A}\left(\pi_{\mathrm{F}}, \pi_{\mathrm{H}}\right)\right)-\frac{1}{2} \mathcal{A}\left(\pi_{\mathrm{H}}, \pi_{\mathrm{H}}\right)\right) X_{t}, \\
& =\left(\pi_{r}+\pi_{e r}^{\mathrm{H}}\right) X_{t} .
\end{aligned}
$$

Combining this expression for expected returns with the assumed form for equilibrium dividends, the dynamics of the state vector, and (26a) gives

$$
\begin{aligned}
p_{t} & =\sum_{i=0}^{\infty} \beta^{i}\left\{(1-\beta) \pi_{d} \mathbb{E}_{t} X_{t+1+i}-\left(\pi_{r}+\pi_{e r}^{\mathrm{H}}\right) \mathbb{E}_{t} X_{t+i}\right\}, \\
& =\left[(1-\beta) \pi_{d} \mathbb{A}-\left(\pi_{r}+\pi_{e r}^{\mathrm{H}}\right)\right](I-\beta \mathbb{A})^{-1} X_{t} .
\end{aligned}
$$

Thus, given our assumption about dividends, the risk free rate, and the optimality of portfolio choices we find that $\log$ equity prices satisfy $p_{t}=\pi_{p} X_{t}$ where

$$
\pi_{p}=\left[(1-\beta) \pi_{d} \mathbb{A}-\left(\pi_{r}+\pi_{e r}^{\mathrm{H}}\right)\right](I-\beta \mathbb{A})^{-1}
$$

A similar exercise confirms that $\hat{p}_{t}=\pi_{\hat{p}} X_{t}$ where

$$
\pi_{\hat{p}}=\left[(1-\beta) \pi_{\hat{d}^{A}} \mathbb{A}-\left(\pi_{\hat{r}}+\pi_{e r}^{\mathrm{F}}\right)\right](I-\beta \mathbb{A})^{-1} .
$$

The restrictions in (32) and (33) depend on the form of the dividend policies via the $\pi_{d}$ and $\pi_{\hat{d}}$ 
vectors. These vectors are determined by the firm's first order conditions. In particular, using the fact that $\mathbb{V}_{t}\left(r_{t+1}^{k}\right)=\psi^{2} \mathbb{V}_{t}\left(z_{t+1}\right)$ and $\mathbb{C V}_{t}\left(r_{t+1}^{k}, w_{t+1}\right)=\psi \mathbb{C V}_{t}\left(z_{t+1}, w_{t+1}\right)$, we can use R1 and R2 to write the log-linearized first order condition for $\mathrm{H}$ firms in (22a) as

$$
\begin{aligned}
\mathbb{E}_{t} r_{t+1}^{k} & =r_{t}+\mathbb{C V}_{t}\left(r_{t+1}^{k}, w_{t+1}\right)-\frac{1}{2} \mathbb{V}_{t}\left(r_{t+1}^{k}\right) \\
& =\left[\pi_{r}+\psi\left(\mathcal{B}\left(\pi_{\alpha}^{\mathrm{H}}, \mathcal{A}\left(\pi_{\mathrm{H}}, h_{z}\right)\right)+\mathcal{B}\left(\pi_{\alpha}^{\mathrm{F}}, \mathcal{A}\left(\pi_{\mathrm{F}}, h_{z}\right)\right)\right)-\frac{1}{2} \psi^{2} \mathcal{A}\left(h_{z}, h_{z}\right)\right] X_{t}
\end{aligned}
$$

At the same time, (23) and (24) imply that

$$
\begin{aligned}
\mathbb{E}_{t} r_{t+1}^{k} & =\psi \mathbb{E}_{t} z_{t+1}-(1-\theta) \psi\left\{\frac{1}{\beta} k_{t}+\frac{\psi}{\beta \theta} z_{t}-\left(\frac{\psi}{\theta \beta}-\delta\right) d_{t}\right\} \\
& =\left[\psi h_{z} \mathbb{A}-(1-\theta) \psi\left\{\frac{1}{\beta} h_{k}+\frac{\psi}{\beta \theta} h_{z}-\left(\frac{\psi}{\theta \beta}-\delta\right) \pi_{d}\right\}\right] X_{t}
\end{aligned}
$$

Combining these expressions and equating coefficients gives

$$
\begin{aligned}
\pi_{d}= & \frac{\theta \beta}{(1-\theta) \psi(\psi-\delta \theta \beta)}\left\{\pi_{r}+\psi\left(\mathcal{B}\left(\pi_{\alpha}^{\mathrm{H}}, \mathcal{A}\left(\pi_{\mathrm{H}}, h_{z}\right)\right)+\mathcal{B}\left(\pi_{\alpha}^{\mathrm{F}}, \mathcal{A}\left(\pi_{\mathrm{F}}, h_{z}\right)\right)\right)-\frac{1}{2} \psi^{2} \mathcal{A}\left(h_{z}, h_{z}\right)-\psi h_{z} \mathbb{A}\right\} \\
& +\frac{1}{(\psi-\delta \theta \beta)}\left\{\theta h_{k}+\psi h_{z}\right\} .
\end{aligned}
$$

The first order condition for F firms gives an analogous expression for $\pi_{\hat{d}}$.

The behavior of the non-predetermined variables must also be consistent with market clearing. According to (21), market clearing in the bonds requires that $p_{t}+\hat{p}_{t}=d_{t}+\hat{d}_{t}$, a condition that implies

$$
\pi_{p}+\pi_{\hat{p}}=\pi_{d}+\pi_{\hat{d}}
$$

In the case of the $\mathrm{H}$ and $\mathrm{F}$ equity markets we need

$$
\begin{aligned}
& 1+p_{t}-w_{t}+\frac{1}{2}\left(p_{t}-w_{t}\right)^{2}=\alpha_{t}^{\mathrm{H}}+\hat{\alpha}_{t}^{\mathrm{H}}\left(1+\hat{w}_{t}-w_{t}+\frac{1}{2}\left(\hat{w}_{t}-w_{t}\right)^{2}\right), \\
& 1+\hat{p}_{t}-\hat{w}_{t}+\frac{1}{2}\left(\hat{p}_{t}-\hat{w}_{t}\right)^{2}=\hat{\alpha}_{t}^{\mathrm{F}}+\alpha_{t}^{\mathrm{F}}\left(1+w_{t}-\hat{w}_{t}+\frac{1}{2}\left(w_{t}-\hat{w}_{t}\right)^{2}\right) .
\end{aligned}
$$

Rewriting these equations in terms of $X_{t}$, applying R2, and equating coefficients gives

$$
\begin{aligned}
h_{1}+\pi_{p}-h_{w}+\frac{1}{2} \mathcal{B}\left(\pi_{p}-h_{w}, \pi_{p}-h_{w}\right) & =\pi_{\alpha}^{\mathrm{H}}+\mathcal{B}\left(\pi_{\hat{\alpha}}^{\mathrm{H}},\left(h_{1}+h_{\hat{w}}-h_{w}+\frac{1}{2} \mathcal{B}\left(h_{\hat{w}}-h_{w}, h_{\hat{w}}-h_{w}\right)\right)\right), \\
h_{1}+\pi_{\hat{p}}-h_{\hat{w}}+\frac{1}{2} \mathcal{B}\left(\pi_{\hat{p}}-h_{\hat{w}}, \pi_{\hat{p}}-h_{w}\right) & =\pi_{\hat{\alpha}}^{\mathrm{F}}+\mathcal{B}\left(\pi_{\alpha}^{\mathrm{F}},\left(h_{1}+h_{w}-h_{\hat{w}}+\frac{1}{2} \mathcal{B}\left(h_{w}-h_{\hat{w}}, h_{w}-h_{\hat{w}}\right)\right)\right) .
\end{aligned}
$$

The remaining market clearing condition comes from the goods market. Walras Law makes this condition redundant when the restrictions implied by the other market clearing conditions are 
imposed, so there is no need to consider its implications directly.

\subsection{Numerical Procedure}

We have described how the log-linearized equations characterizing the equilibrium of the model are used to derive a set of restrictions on the behavior of the state vector and the non-predetermined variables. A solution to the model requires that we find values for all the parameters in process for $X_{t}$ and $Y_{t}$ that satisfy these restrictions given values for the exogenous taste and technology parameters. More formally, we need to find all the elements of $\mathbb{A}, \Pi$ and $\mathcal{S}($.$) such that$

$$
\mathcal{F}\left(\Pi \mathbb{A} X_{t}+\Pi U_{t+1}, \Pi X_{t}, \mathbb{A} X_{t}+U_{t+1}, X_{t}, \mathcal{S}\left(X_{t}\right)\right)=0
$$

where $\mathcal{F}($.$) consists of all the equilibrium conditions, including the restrictions on the second mo-$ ments, implied by the model.

We proceed in the following steps:

1. For the given set of exogenous parameter values we conjecture some initial values for policy matrix $\Pi^{(1)}$ and the coefficient matrices $\left\{\Phi_{0}^{(1)}, \Phi_{1}^{(1)}, \Phi_{2}^{(1)}\right\}$ governing the state vector dynamics. We also need to choose starting values for $\left\{\Omega_{0}, \Omega_{1}\right\}$ and arrange them into $[\Sigma]_{i}$ (the rows of $\Sigma) . \Sigma$ characterizes the heteroskedastic nature of the variance-covariance matrix of the state vector. We start with a homoskedastic guess:

$$
\begin{aligned}
& {[\Sigma]_{i}^{(1)}=\left[\begin{array}{cc}
\sigma_{e}^{2} & \mathbf{0}_{1 \times(k-1)}
\end{array}\right], \quad i=\left\{V_{t}(z)\right\}} \\
& {[\Sigma]_{i}^{(1)}=\left[\mathbf{0}_{1 \times k}\right], \quad i \neq\left\{V_{t}(z)\right\} .}
\end{aligned}
$$

2. With these guesses we can construct a coefficient matrix $\mathbb{A}^{(1)}$ from (30) and variance-covariance function $\mathcal{S}^{(1)}$ from $(31)$.

3. Now we form the value function

$$
\mathcal{J}^{1}\left(\Pi^{(1)}\right)=\mathcal{F}\left(\Pi^{(1)} \mathbb{A}^{(1)} X_{t}+\Pi^{(1)} U_{t+1}, \Pi^{(1)} X_{t}, \mathbb{A}^{(1)} X_{t}+U_{t+1}, X_{t}, \mathcal{S}^{(1)}\left(X_{t}\right)\right)
$$

4. For the given values of $\mathbb{A}$ and $\mathcal{S}$ find $\Pi^{(2)}$ as the solution to $\mathcal{J}^{1}\left(\Pi^{(1)}\right)=0$. If $\Pi^{(2)}$ differs from $\Pi^{(1)}$, we return to step 2 . The procedure stops when $\Pi^{(\tau)}=\Pi^{(\tau-1)}$. 


\section{Results}

The one-sector model provides an environment in which we can assess the accuracy of our solution method. In particular, the structure of the model is sufficiently simple for us to analytically determine the equilibrium portfolio holdings of households. We can therefore compare these holdings to those implied by the numerical solution to the model.

The analytic solution to the model is based on the observation that the array of assets available to households (i.e., equity issued by $\mathrm{H}$ and $\mathrm{F}$ firms and risk free bonds) permits complete risksharing. We can see why this is so by returning to conditions determining the household portfolio choices. In particular, combining the log-linearized first order conditions with the budget constraint as shown in (19) under the assumption of log preferences, we obtain

$$
\boldsymbol{\alpha}_{t}=\Theta_{t}^{-1}\left(\mathbb{E}_{t} e r_{t+1}+\frac{1}{2} \operatorname{diag}\left(\Theta_{t}\right)\right) \quad \text { and } \quad \hat{\boldsymbol{\alpha}}_{t}=\Theta_{t}^{-1}\left(\mathbb{E}_{t} e r_{t+1}+\frac{1}{2} \operatorname{diag}\left(\Theta_{t}\right)\right)
$$

where, as before, $\boldsymbol{\alpha}_{t}^{\prime} \equiv\left[\begin{array}{cc}\alpha_{t}^{\mathrm{H}} & \alpha_{t}^{\mathrm{F}}\end{array}\right], \hat{\boldsymbol{\alpha}}_{t}^{\prime} \equiv\left[\begin{array}{cc}\hat{\alpha}_{t}^{\mathrm{H}} & \hat{\alpha}_{t}^{\mathrm{F}}\end{array}\right], e r_{t+1}^{\prime} \equiv\left[\begin{array}{ll}r_{t+1}^{\mathrm{H}}-r_{t} & r_{t+1}^{\mathrm{F}}-r_{t}\end{array}\right]$, and $\Theta_{t} \equiv$ $\mathbb{V}_{t}\left(e r_{t+1}\right)$. The key point to note here is that all households face the same set of returns and have the same information. So the right hand side of both expressions in (34) are identical in equilibrium. $\mathrm{H}$ and $\mathrm{F}$ households will therefore find it optimal to hold the same portfolio shares. This has a number of implications if the initial distribution of wealth is equal. First, household wealth will be equalized across countries. Second, since households with log utility consume a constant fraction of wealth, consumption will also be equalized. This symmetry in household behavior together with the market clearing conditions implies that bond holdings are zero and wealth is equally split between $\mathrm{H}$ and $\mathrm{F}$ equities (i.e., $\alpha_{t}^{\mathrm{H}}=\hat{\alpha}_{t}^{\mathrm{H}}=\alpha_{t}^{\mathrm{F}}=\hat{\alpha}_{t}^{\mathrm{F}}=1 / 2$ ). The symmetry in consumption also implies that $m_{t+1}=\hat{m}_{t+1}$ so risk sharing is complete.

Table 1 reports statistics on the simulated portfolio holdings of households computed from the numerical solution to the model. For this purpose we used the solution method described above to find the parameters of $X_{t}$ and $Y_{t}$ processes consistent with the log-linearized equilibrium conditions. These calculations were performed assuming a discount factor $\beta$ equal to 0.99 , the technology share parameter $\theta$ equal to 0.36 and a depreciation rate for capital, $\delta$, of 0.02 . The $\log$ of $\mathrm{H}$ and $\mathrm{F}$ productivity, $z_{t}$ and $\hat{z}_{t}$, are assumed to follow independent $\operatorname{AR}(1)$ processes with the same autocorrelation coefficient, $a_{i i}, i=\{\mathrm{H}, \mathrm{F}\}$, equal to 0.95 and innovation variance $\sigma_{e}^{2}$ equal to 0.0001. Once the model is "solved", we simulate $X_{t}$ over 500 quarters starting from an equal wealth distribution. We then discard the first 100 quarters from each simulation. The statistics we report in Table 1 are derived from 100 simulations and so are based on 10,000 years of simulated quarterly 
data in the neighborhood of the initial wealth distribution. ${ }^{7}$

Table 1: Simulated Portfolio Holdings (One Sector Model)

\begin{tabular}{lccc}
\hline \hline & $\begin{array}{c}A_{t}^{\mathrm{H}} \\
(\mathrm{i})\end{array}$ & $\begin{array}{c}A_{t}^{\mathrm{F}} \\
(\mathrm{ii})\end{array}$ & $\begin{array}{c}B_{t} \\
(\mathrm{iii})\end{array}$ \\
\hline & & & $\% \mathrm{GDP}$ \\
mean & 0.5000 & 0.5000 & $0.00 \%$ \\
std dev & 0.0000 & 0.0000 & $0.25 \%$ \\
min & 0.4999 & 0.4999 & $-1.52 \%$ \\
$\max$ & 0.5001 & 0.5001 & $2.53 \%$ \\
\hline \hline
\end{tabular}

Columns (i), (ii) and (iii) report statistics on the asset holdings of $\mathrm{H}$ households computed from the model simulations. Theoretically speaking, we should see that $B_{t}=0$ and $A_{t}^{\mathrm{H}}=A_{t}^{\mathrm{F}}=0.5$. (Recall that the supply of $\mathrm{H}$ and $\mathrm{F}$ equity are both normalized to unity.) The simulation results conform closely to these predictions. The equity portfolio holdings show no variation and on average are exactly as theory predicts. Average bond holdings, measured as a share of model's GDP are similarly close to zero, but show a little more variation. Overall, simulations based on our solution technique appear to closely replicate the complete risk sharing allocation theory predicts.

\section{The Two-Sector Model}

The power of our solution procedure resides in its applicability to models with portfolio choice and incomplete markets. Analytic solutions are unavailable in these models and existing numerical solution methods are inapplicable. In this section we consider a two-sector extension of the model in which markets are incomplete.

\subsection{The Model}

In this version of the model households in the two countries have preferences defined over the consumption of two goods: a tradeable and nontradeable. The preferences of a representative household in the $\mathrm{H}$ country are given by

$$
\mathbb{U}_{t}=\mathbb{E}_{t} \sum_{i=0}^{\infty} \beta^{i} U\left(C_{t+i}^{\mathrm{T}}, C_{t+i}^{\mathrm{N}}\right),
$$

\footnotetext{
${ }^{7}$ The innovations to equilibrium wealth are small enough to keep $\mathrm{H}$ and $\mathrm{F}$ wealth close to its initial levels over a span of 500 quarters so the approximation error in (27) remains very small.
} 
where $0<\beta<1$ is the discount factor, and $U($.$) is a concave sub-utility function defined over the$ consumption of traded and non-traded goods, $C_{t}^{\mathrm{T}}$ and $C_{t}^{\mathrm{N}}$ :

$$
U\left(C^{\mathrm{T}}, C^{\mathrm{N}}\right)=\frac{1}{\phi} \ln \left[\lambda_{\mathrm{T}}^{1-\phi}\left(C^{\mathrm{T}}\right)^{\phi}+\lambda_{\mathrm{N}}^{1-\phi}\left(C^{\mathrm{N}}\right)^{\phi}\right]
$$

with $\phi<1 . \lambda_{\mathrm{T}}$ and $\lambda_{\mathrm{N}}$ are the weights the household assigns to tradeable and nontradeable consumption respectively. The elasticity of substitution between tradeable and nontradeable consumption is $(1-\phi)^{-1}>0$. Preferences for households in country F are similarly defined in terms of foreign consumption of tradeables and non-tradeables, $\hat{C}_{t}^{\mathrm{T}}$ and $\hat{C}_{t}^{\mathrm{N}}$. Notice that preferences are not separable across the two consumption goods.

The menu of assets available to households now includes the equity issued by $\mathrm{H}$ and $\mathrm{F}$ firms producing tradeable goods, risk free bonds, and the equity issued by domestic firms producing nontradeable goods. Households are not permitted to hold the equity of foreign firms producing nontradeable goods. With the new array of assets, the budget constraint for $\mathrm{H}$ households becomes

$$
W_{t+1}=R_{t+1}^{\mathrm{W}}\left(W_{t}-C_{t}^{\mathrm{T}}-Q_{t}^{\mathrm{N}} C_{t}^{\mathrm{N}}\right)
$$

where

$$
R_{t+1}^{\mathrm{W}}=R_{t}+\alpha_{t}^{\mathrm{H}}\left(R_{t+1}^{\mathrm{H}}-R_{t}\right)+\alpha_{t}^{\mathrm{F}}\left(R_{t+1}^{\mathrm{F}}-R_{t}\right)+\alpha_{t}^{\mathrm{N}}\left(R_{t+1}^{\mathrm{N}}-R_{t}\right) .
$$

$Q_{t}^{\mathrm{N}}$ is the relative price of $\mathrm{H}$ nontradeables in terms of tradeables, and $R_{t+1}^{\mathrm{N}}$ is the return on equity issued by domestic firms producing nontradeables, measured in terms of tradeables:

$$
R_{t+1}^{\mathrm{N}}=\left\{\left(P_{t+1}^{\mathrm{N}}+D_{t+1}^{\mathrm{N}}\right) / P_{t}^{\mathrm{N}}\right\}\left\{Q_{t+1} / Q_{t}\right\}
$$

$P_{t}^{\mathrm{N}}$ is the price of equity issued by $\mathrm{H}$ firms producing nontradeables and $D_{t}^{\mathrm{N}}$ is the flow of dividends, both measured in terms of nontradeables. The budget constraint and returns on F household wealth are analogously defined (see Evans and Hnatkovska, 2005, for details).

The production side of the model remains unchanged aside from the addition of the nontradeable sector in each country. For simplicity we assume that the production of nontradeables requires no capital. Nontradeable output, $Y_{t}^{\mathrm{N}}$ and $\hat{Y}_{t}^{\mathrm{N}}$, in countries $\mathrm{H}$ and $\mathrm{F}$ is given by

$$
Y_{t}^{\mathrm{N}}=\eta Z_{t}^{\mathrm{N}}, \quad \text { and } \quad \hat{Y}_{t}^{\mathrm{N}}=\eta \hat{Z}_{t}^{\mathrm{N}},
$$

where $\eta>0$ is a constant. $Z_{t}^{\mathrm{N}}$ and $\hat{Z}_{t}^{\mathrm{N}}$ denote the period- $t$ state of nontradeable productivity in countries $\mathrm{H}$ and F respectively. The productivity vector is now $z_{t} \equiv\left[\ln Z_{t}^{\mathrm{T}}, \ln \hat{Z}_{t}^{\mathrm{T}}, \ln Z_{t}^{\mathrm{N}}, \ln \hat{Z}_{t}^{\mathrm{N}}\right]^{\prime}$. We 
continue to assume that $z_{t}$ follows an $\mathrm{AR}(1)$ process:

$$
z_{t}=a z_{t-1}+e_{t}
$$

where $e_{t}$ is a $4 \times 1$ vector of i.i.d. mean zero shocks with covariance $\Omega_{e}$.

\subsection{Equilibrium}

As in a one-sector model, the equilibrium conditions comprise the first-order conditions of households and firms and the market clearing conditions. Since the production of nontradeable output requires no capital, firms in this sector simply pass on their revenues to shareholders in the form of dividends. In the tradeable sector, the first-order conditions governing dividends remain unchanged. Optimal household behavior now covers the choice between different consumption goods, and a wider array of financial assets. The first-order conditions for $\mathrm{H}$ households, in addition to (8), now include

$$
\begin{aligned}
Q_{t}^{\mathrm{N}} & =\frac{\partial U / \partial C_{t}^{\mathrm{N}}}{\partial U / \partial C_{t}^{\mathrm{T}}}, \\
1 & =\mathbb{E}_{t}\left[M_{t+1} R_{t+1}^{\mathrm{N}}\right]
\end{aligned}
$$

where $M_{t+1} \equiv \beta\left(\partial U / \partial C_{t+1}^{\mathrm{T}}\right) /\left(\partial U / \partial C_{t}^{\mathrm{T}}\right)$. The first order conditions for $\mathrm{F}$ households are expanded in an analogous manner.

Solving for an equilibrium now requires finding equity prices, $\left\{P_{t}^{\mathrm{H}}, P_{t}^{\mathrm{F}}, P_{t}^{\mathrm{N}}, \hat{P}_{t}^{\mathrm{N}}\right\}$, goods prices, $\left\{Q_{t}^{\mathrm{N}}, \hat{Q}_{t}^{\mathrm{N}}\right\}$, and the interest rate, $R_{t}$, such that markets clear when households follow optimal consumption, saving and portfolio strategies, and firms in the tradeable sector make optimal investment decisions. As above, we assume that bonds are in zero net supply so that (10) continues to be the bond market clearing condition. Similarly, equation (11) is the market clearing condition in tradeable goods market. Market clearing in the non-tradeable sector of each country requires that

$$
C_{t}^{\mathrm{N}}=Y_{t}^{\mathrm{N}}=D_{t}^{\mathrm{N}}, \quad \text { and } \quad \hat{C}_{t}^{\mathrm{N}}=\hat{Y}_{t}^{\mathrm{N}}=\hat{D}_{t}^{\mathrm{N}}
$$

As above, we normalize the number of outstanding shares issued by firms in each sector to unity so market clearing in the equity markets requires that

$$
\begin{array}{ll}
1=A_{t}^{\mathrm{H}}+\hat{A}_{t}^{\mathrm{H}}, & 1=A_{t}^{\mathrm{F}}+\hat{A}_{t}^{\mathrm{F}}, \\
1=A_{t}^{\mathrm{N}}, & 1=\hat{A}_{t}^{\mathrm{N}} .
\end{array}
$$


$A_{t}^{\mathrm{N}}$ and $\hat{A}_{t}^{\mathrm{N}}$ are the number of shares held by $\mathrm{H}$ and $\mathrm{F}$ households in domestic nontradeable firms.

\subsection{Results}

Table 2 reports statistics on the simulated portfolio holdings of households computed from the numerical solution to the two-sector model. This is a complex model and is analyzed in depth in Evans and Hnatkovska (2005). That paper also presents the log-linearized equilibrium conditions used in the solution procedure. The results in Table 2 are based on the same values for $\beta, \theta, \delta$, and $\sigma_{e}^{2}$. In addition, we set the share parameters $\lambda^{\mathrm{T}}$ and $\hat{\lambda}^{\mathrm{T}}$ equal 0.5 , the elasticity of substitution $1 /(1-\phi)$ equal to 0.74 , the autocorrelation in nontradeable productivity to 0.99 , while in tradeable productivity to 0.78. Innovations to nontradeable productivity are assumed to be i.i.d. with variance equal to $\sigma_{e}^{2}$. As above, the statistics are computed from model simulations covering 10,000 years of quarterly data.

Table 2: Simulated Portfolio Holdings (Two Sector Model)

\begin{tabular}{ccccc}
\hline \hline & $A_{t}^{\mathrm{H}}$ & $A_{t}^{\mathrm{F}}$ & $A_{t}^{\mathrm{N}}$ & $B_{t}$ \\
$(\mathrm{i})$ & $(\mathrm{ii})$ & $(\mathrm{iii})$ & (iv) \\
\hline & & & & $\%$ GDP \\
mean & 0.5000 & 0.5000 & 1.0000 & $-0.23 \%$ \\
std dev & 0.0019 & 0.0019 & 0.0000 & $12.19 \%$ \\
$\min$ & 0.4918 & 0.4925 & 1.0000 & $-40.29 \%$ \\
$\max$ & 0.5076 & 0.5077 & 1.0000 & $71.19 \%$ \\
\hline \hline
\end{tabular}

Columns (i) - (iv) report statistics on the asset holdings of $\mathrm{H}$ households computed from the model simulations. As in the one-sector model, households continue to diversify their holdings between the equity issued by $\mathrm{H}$ and $\mathrm{F}$ firms producing tradeable goods. (Household holdings of equity issued by domestic firms producing nontradeable goods must equal unity in order to clear the market.) While these holdings are split equally on average, they are far from constant. Both the standard deviation and range of the tradeable equity holdings are an order of magnitude larger than the simulated holdings from the one-sector model. Differences between the one- and twosector models are even more pronounced for bond holdings. In the two-sector model shocks to productivity in the nontradeable sector affect $\mathrm{H}$ and $\mathrm{F}$ households differently and create incentives for international borrowing and lending. In equilibrium most of this activity takes place via trading in the bond market, so bond holdings display a good deal of volatility in our simulations. 


\section{Conclusion}

We have presented a numerical method for solving general equilibrium models with many assets, heterogeneous agents and incomplete markets. Our method builds on the log-linear approximations of Campbell, Chan and Viceira (2003) and the second-order perturbation techniques developed by Judd (1998) and others. To illustrate its use, we have applied our solution method to a one- and two-sector versions of a two country general equilibrium model with production. The numerical solution to the one-sector model closely conforms to the predictions of theory and gives us confidence in the accuracy of the method. The power of our method is illustrated by solving the two-sector version of the model. The array of assets in this model is insufficient to permit complete risk sharing among households, so the equilibrium allocations cannot be found by standard analytic techniques. To the best of our knowledge, our method provides the only way to analyze general equilibrium models with portfolio choice and incomplete markets.

In principle, our solution method can be applied to more complicated models than the one- and two-sector models described above. For example, the method can be applied to solve models with more complex preferences, capital adjustment costs, or portfolio constraints. The only requirement is that the equilibrium conditions can be expressed in a log-linear form. We believe that the solution method presented here will be useful in the future analysis of such models. 


\section{References}

[1] Barberis, Nicholas (2000). "Investing for the Long Run when Returns are Predictable", Journal of Finance, Vol. 55, No. 1, pp. 225-264.

[2] Baxter, Marianne, Urban J. Jermann, and Robert G. King (1998). "Nontraded Goods, Nontraded Factors and International Non-diversification", Journal of International Economics Vol. 44, pp. 211-229.

[3] Brandt, Michael W., Amit Goyal, and Pedro Santa-Clara (2001). "Dynamic Portfolio Choice: A Simulation Approach", Anderson Graduate School of Management Finance Paper No. 4-01.

[4] _ _ _ _ and Pedro Santa-Clara (2004). "Dynamic Portfolio Selection by Augmenting the Asset Space".

[5] Brennan, Michael J., Eduardo S. Schwartz, Ronald Lagnado (1997). "Strategic Asset Allocation", Journal of Economic Dynamics and Control, Vol. 21, pp. 137r-1403.

[6] Campbell, John Y. and Robert J. Shiller (1989). "The Dividend-Price Ratio and Expectations of Future Dividends and Discount Factors", The Review of Financial Studies, Vol. 1, No. 3, pp. 195-228.

[7] Campbell, John Y. and Luis M. Viceira (2001). "Strategic Asset Allocation: Portfolio Choice of Long-term Investors".

[8] Campbell, JohnY., Yeung Lewis Chan, and Luis M. Viceira (2003). "A Multivariate Model of Strategic Asset Allocation", Journal of Financial Economics, Vol. 67, No. 1, pp. 41-80.

[9] Collard, Fabrice and Michel Juillard (2001). "Accuracy of Stochastic Perturbation Methods: The Case of Asset Pricing Models", Journal of Economic Dynamics and Control, Vol. 25, pp. 979-999.

[10] Danthine, Jean-Pierre and John B. Donaldson (1994). "Asset Pricing Implications of Real Market Frictions".

[11] Dumas, Bernard (1989). "Two-Person Dynamic Equilibrium in the Capital Market", The Review of Financial Studies, Vol. 2, No. 2, pp. 157-188.

[12] Engel, Charles and Akito Matsumoto (2004). "Home Bias Under New Open Economy Macroeconomics". 
[13] Epaulard, Anne and Aude Pommeret (2005). "Financial Integration, Growth, and Volatility", IMF Working Paper 05/67.

[14] Evans, Martin D. D. and Viktoria V. Hnatkovska (2005). "International Capital Flows, Returns and World Financial Integration".

[15] Heathcote, Jonathan and Fabrizio Perri (2004). "The International Diversification Puzzle is not as Bad as You Think", Georgetown University Working Paper.

[16] Jin, He-Hui and Kenneth L. Judd (2002). "Perturbation Methods for General Dynamic Stochastic Models".

[17] Judd, Kenneth L. (1998). "Numerical Methods in Economics", MIT Press.

[18] Judd, Kenneth L. and Sy-Ming Guu (1993). "Perturbation Solution Methods for Economic Growth Models", in Economic and Financial Modeling with Mathematica, Hal Varian, ed., Springer-Verlag: New York.

[19] ______ (1997). "Asymptotic Methods for Aggregate Growth Models", Journal of Economic Dynamics and Control, Vol. 21, No.6, pp. 1025-1042.

[20] _- _-_ (2000). "The Economic Effects of New Assets: An Asymptotic Approach".

[21] Kim, Tong Suk and Edward Omberg (1996). "Dynamic Nonmyopic Portfolio Behavior", The Review of Financial Studies, Vol. 9, No. 1, pp. 141-161.

[22] Kogan, Leonid and Raman Uppal (2000). "Risk Aversion and Optimal Portfolio Policies in Partial and General Equilibrium Economies".

[23] Kollmann, Robert (2005). " A Dynamic Equilibrium Model of International Portfolio Holdings: Comment", University of Paris XII Working Paper.

[24] Liu, Jun (2005). "Portfolio Selection in Stochastic Environments".

[25] Lucas, Robert E. (1978). "Asset Prices in an Exchange Economy", Econometrica, Vol. 46, No. 6, pp. $1429-1445$.

[26] Markowitz, Harry (1952). "Portfolio Selection", The Journal of Finance, Vol. 7, No. 1, pp. $77-91$. 
[27] Merton, Robert C. (1969). "Lifetime Portfolio Selection under Uncertainty: The Continuoustime Case", The Review of Economics and Statistics, Vol. 51, No. 3, pp. 247-25\%.

[28] _______ (1971). "Optimum Consumption and Portfolio Rules in a Continuous-time Model", Journal of Economic Theory, Vol. 3, pp. 373-413.

[29] ______ (1973). "An Intertemporal Capital Asset Pricing Model", Econometrica, Vol. 41, No. 5 , pp. $867-887$.

[30] Michaelides, Alexander (2003). "International Portfolio Choice, Liquidity Constraints and the Home Equity Bias Puzzle", London School of Economic Working Paper.

[31] Miranda, Mario J. and Paul L. Fackler (2002). "Applied Computational Economics and Finance", The MIT Press, Cambridge, Massachusetts.

[32] Pesenti, Paolo and Eric van Wincoop (1996). "Do Nontraded Goods Explain the Home Bias Puzzle?" NBER Working Paper 5784.

[33] Samuelson, Paul A. (1969). "Lifetime Portfolio Selection by Dynamic Stochastic Programming", The Review of Economics and Statistics Vol. 51, No.3, pp. 239-246.

[34] Sercu, Piet, Raman Uppal, and Cynthia Van Hulle (1999). "International Portfolio Choice and Home Bias: The Effects of Commodity Market Imperfections".

[35] Serrat, Angel (2001). "A Dynamic Equilibrium Model of International Portfolio Holdings", Econometrica, Vol. 69, No. 6, pp. 1467-1489.

[36] Schmitt-Grohe, Stephanie and Martin Uribe (2004). "Solving Dynamic General Equilibrium Models Using a Second-order Approximation to the Policy Function", Journal of Economic Dynamics and Control, Vol. 28, pp. 755-775.

[37] Uppal, Raman (1993). "A General Equilibrium Model of International Portfolio Choice", The Journal of Finance, Vol. 48, No. 2, pp. 529-553. 


\section{A Appendix:}

\section{A.1 Derivation of (29)}

We start with quadratic and cross-product terms, $\tilde{x}_{t}$ and approximate their laws of motion using Ito's lemma. In continuous time, the discrete process for $x_{t+1}$ in (27) becomes

$$
d x_{t}=\left[\Phi_{0}-\Phi_{1} x_{t}+\Phi_{2} \tilde{x}_{t}\right] d t+\Omega\left(\tilde{x}_{t}\right)^{1 / 2} d W_{t}
$$

Then by Ito's lemma:

$$
\begin{aligned}
\operatorname{dvec}\left(x_{t} x_{t}^{\prime}\right)= & {\left[\left(I \otimes x_{t}\right)+\left(x_{t} \otimes I\right)\right]\left(\left[\Phi_{0}-\Phi_{1} x_{t}+\Phi_{2} \tilde{x}_{t}\right] d t+\Omega\left(\tilde{x}_{t}\right)^{1 / 2} d W_{t}\right) } \\
& +\frac{1}{2}\left[(I \otimes U)\left(\frac{\partial x}{\partial x^{\prime}} \otimes I\right)+\left(\frac{\partial x}{\partial x^{\prime}} \otimes I\right)\right] d[x, x]_{t} \\
= & {\left[\left(I \otimes x_{t}\right)+\left(x_{t} \otimes I\right)\right]\left(\left[\Phi_{0}-\Phi_{1} x_{t}+\Phi_{2} \tilde{x}_{t}\right] d t+\Omega\left(\tilde{x}_{t}\right)^{1 / 2} d W_{t}\right) } \\
& +\frac{1}{2}\left[\mathbb{U}\left(\frac{\partial x}{\partial x^{\prime}} \otimes I\right)+\left(\frac{\partial x}{\partial x^{\prime}} \otimes I\right)\right] \operatorname{vec}\left\{\Omega\left(\tilde{x}_{t}\right)\right\} d t \\
= & {\left[\left(I \otimes x_{t}\right)+\left(x_{t} \otimes I\right)\right]\left(\left[\Phi_{0}-\Phi_{1} x_{t}+\Phi_{2} \tilde{x}_{t}\right] d t+\Omega\left(\tilde{x}_{t}\right)^{1 / 2} d W_{t}\right)+\frac{1}{2} \operatorname{Dvec}\left\{\Omega\left(\tilde{x}_{t}\right)\right\} d t,(\mathrm{~A} 1) } \\
\text { where } \quad & D=\left[\mathbb{U}\left(\frac{\partial x}{\partial x^{\prime}} \otimes I\right)+\left(\frac{\partial x}{\partial x^{\prime}} \otimes I\right)\right], \quad \mathbb{U}=\sum_{r} \sum_{s} E_{r s} \otimes E_{r, s}^{\prime},
\end{aligned}
$$

and $E_{r, s}$ is the elementary matrix which has a unity at the $(r, s)^{t h}$ position and zero elsewhere. The law of motion for the quadratic states in (A1) can be rewritten in discrete time as

$$
\begin{aligned}
\tilde{x}_{t+1} \cong & \tilde{x}_{t}+\left[\left(I \otimes x_{t}\right)+\left(x_{t} \otimes I\right)\right]\left[\Phi_{0}-\Phi_{1} x_{t}+\Phi_{2} \tilde{x}_{t}\right]+\frac{1}{2} \operatorname{Dvec}\left(\Omega\left(\tilde{x}_{t}\right)\right) \\
& +\left[\left(I \otimes x_{t}\right)+\left(x_{t} \otimes I\right)\right] \varepsilon_{t+1}, \\
\cong & \frac{1}{2} D \Sigma_{0}+\left[\left(\Phi_{0} \otimes I\right)+\left(I \otimes \Phi_{0}\right)\right] x_{t}+\left[I-\left(\Phi_{1} \otimes I\right)-\left(I \otimes \Phi_{1}\right)+\frac{1}{2} D \Sigma_{1}\right] \tilde{x}_{t}+\tilde{\varepsilon}_{t+1},
\end{aligned}
$$

where $\tilde{\varepsilon}_{t+1} \equiv\left[\left(I \otimes x_{t}\right)+\left(x_{t} \otimes I\right)\right] \varepsilon_{t+1}$. The last equality is obtained by using an expression for $\operatorname{vec}\left(\Omega\left(X_{t}\right)\right)$ in (28), where $\Sigma_{0}=\operatorname{vec}\left(\Omega_{0}\right)$ and $\Sigma_{1}=\Omega_{1} \otimes \Omega_{1}$, and by combining together the corresponding coefficients on a constant, linear and second-order terms. 


\section{A.2 Derivation of (31)}

Recall that $U_{t+1}=\left[\begin{array}{lll}0 & \varepsilon_{t+1} & \tilde{\varepsilon}_{t+1}\end{array}\right]^{\prime}$, so $\mathbb{E}\left(U_{t+1} \mid X_{t}\right)=0$ and

$$
\mathbb{E}\left(U_{t+1} U_{t+1}^{\prime} \mid X_{t}\right) \equiv \mathcal{S}\left(X_{t}\right)=\left(\begin{array}{ccc}
0 & 0 & 0 \\
0 & \Omega\left(X_{t}\right) & \Gamma\left(X_{t}\right) \\
0 & \Gamma\left(X_{t}\right)^{\prime} & \Psi\left(X_{t}\right)
\end{array}\right)
$$

To evaluate the covariance matrix, we assume that $\operatorname{vec}\left(x_{t+1} \tilde{x}_{t+1}^{\prime}\right) \cong 0$ and define:

$$
\begin{aligned}
\Gamma\left(X_{t}\right) \equiv & \mathbb{E}_{t} \varepsilon_{t+1} \tilde{\varepsilon}_{t+1}^{\prime}, \\
= & \mathbb{E}_{t} x_{t+1} \tilde{x}_{t+1}^{\prime}-\mathbb{E}_{t} x_{t+1} \mathbb{E}_{t} \tilde{x}_{t+1}^{\prime}, \\
= & \mathbb{E}_{t} x_{t+1} \tilde{x}_{t+1}^{\prime}-\left(\Phi_{0}+\left(I-\Phi_{1}\right) x_{t}+\Phi_{2} \tilde{x}_{t}\right) \\
& \times\left(\frac{1}{2} \Sigma_{0}^{\prime} D^{\prime}+x_{t}^{\prime}\left[\left(\Phi_{0} \otimes I\right)+\left(I \otimes \Phi_{0}\right)\right]^{\prime}+\tilde{x}_{t}^{\prime}\left[I-\left(\left(\Phi_{1} \otimes I\right)+\left(I \otimes \Phi_{1}\right)\right)+\frac{1}{2} D \Sigma_{1}\right]^{\prime}\right), \\
\cong & -\Phi_{0}\left(\frac{1}{2} \Sigma_{0}^{\prime} D^{\prime}+x_{t}^{\prime}\left[\left(\Phi_{0} \otimes I\right)+\left(I \otimes \Phi_{0}\right)\right]^{\prime}+\tilde{x}_{t}^{\prime}\left[I-\left(\left(\Phi_{1} \otimes I\right)+\left(I \otimes \Phi_{1}\right)\right)+\frac{1}{2} D \Sigma_{1}\right]^{\prime}\right) \\
& -\left(I-\Phi_{1}\right) x_{t}\left(\frac{1}{2} \Sigma_{0}^{\prime} D^{\prime}+x_{t}^{\prime}\left[\left(\Phi_{0} \otimes I\right)+\left(I \otimes \Phi_{0}\right)\right]^{\prime}\right)-\frac{1}{2} \Phi_{2} \tilde{x}_{t} \Sigma_{0}^{\prime} D^{\prime}, \\
= & -\frac{1}{2} \Phi_{0} \Sigma_{0}^{\prime} D^{\prime}-\Phi_{0} x_{t}^{\prime}\left[\left(\Phi_{0} \otimes I\right)+\left(I \otimes \Phi_{0}\right)\right]^{\prime}-\frac{1}{2}\left(I-\Phi_{1}\right) x_{t} \Sigma_{0}^{\prime} D^{\prime} \\
& -\Phi_{0} \tilde{x}_{t}^{\prime}\left[I-\left(\left(\Phi_{1} \otimes I\right)+\left(I \otimes \Phi_{1}\right)\right)+\frac{1}{2} D \Sigma_{1}\right]^{\prime} \\
& -\left(I-\Phi_{1}\right) x_{t} x_{t}^{\prime}\left[\left(\Phi_{0} \otimes I\right)+\left(I \otimes \Phi_{0}\right)\right]^{\prime}-\frac{1}{2} \Phi_{2} \tilde{x}_{t} \Sigma_{0}^{\prime} D^{\prime} .
\end{aligned}
$$

Hence

$$
\begin{aligned}
\operatorname{vec}\left(\Gamma\left(X_{t}\right)\right)= & \Gamma_{0}+\Gamma_{1} x_{t}+\Gamma_{2} \tilde{x}_{t} \\
\Gamma_{0}= & -\frac{1}{2}\left(D \Sigma_{0} \otimes \Phi_{0}\right) \operatorname{vec}(I), \\
\Gamma_{1}= & -\left[\left(\Phi_{0} \otimes I\right)+\left(I \otimes \Phi_{0}\right)\right] \otimes \Phi_{0}+\frac{1}{2}\left(D \Sigma_{0} \otimes\left(I-\Phi_{1}\right)\right) \\
\Gamma_{2}= & -\left[I-\left(\left(\Phi_{1} \otimes I\right)+\left(I \otimes \Phi_{1}\right)\right)+\frac{1}{2} D \Sigma_{1}\right] \otimes \Phi_{0}-\frac{1}{2}\left(D \Sigma_{0} \otimes \Phi_{2}\right) \\
& -\left[\left(\Phi_{0} \otimes I\right)+\left(I \otimes \Phi_{0}\right)\right] \otimes\left(I-\Phi_{1}\right) .
\end{aligned}
$$

Note also from above that

$$
\begin{aligned}
\Gamma\left(X_{t}\right)^{\prime}= & -\frac{1}{2} D \Sigma_{0} \Phi_{0}^{\prime}-\left[\left(\Phi_{0} \otimes I\right)+\left(I \otimes \Phi_{0}\right)\right] x_{t} \Phi_{0}^{\prime}-\Sigma_{0} x_{t}^{\prime}\left(I-\Phi_{1}\right)^{\prime} \\
& -\left[I-\left(\left(\Phi_{1} \otimes I\right)+\left(I \otimes \Phi_{1}\right)\right)+\frac{1}{2} D \Sigma_{1}\right] \tilde{x}_{t} \Phi_{0}^{\prime} \\
& -\left[\left(\Phi_{0} \otimes I\right)+\left(I \otimes \Phi_{0}\right)\right] x_{t} x_{t}^{\prime}\left(I-\Phi_{1}\right)^{\prime}-\frac{1}{2} D \Sigma_{0} \tilde{x}_{t}^{\prime} \Phi_{2}^{\prime} .
\end{aligned}
$$


So

$$
\begin{aligned}
\operatorname{vec}\left(\Gamma\left(X_{t}\right)^{\prime}\right)= & \Lambda_{0}+\Lambda_{1} x_{t}+\Lambda_{2} \tilde{x}_{t} \\
\Lambda_{0}= & -\frac{1}{2}\left(\Phi_{0} \otimes D \Sigma_{0}\right) \operatorname{vec}(I), \\
\Lambda_{1}= & -\left(\Phi_{0} \otimes\left[\left(\Phi_{0} \otimes I\right)+\left(I \otimes \Phi_{0}\right)\right]\right)+\frac{1}{2}\left(\left(I-\Phi_{1}\right) \otimes D \Sigma_{0}\right), \\
\Lambda_{2}= & -\left(\Phi_{0} \otimes\left[I-\left(\left(\Phi_{1} \otimes I\right)+\left(I \otimes \Phi_{1}\right)\right)+\frac{1}{2} D \Sigma_{1}\right]\right)-\frac{1}{2}\left(\Phi_{2} \otimes D \Sigma_{0}\right) \\
& -\left(\left(I-\Phi_{1}\right) \otimes\left[\left(\Phi_{0} \otimes I\right)+\left(I \otimes \Phi_{0}\right)\right]\right) .
\end{aligned}
$$

Next, consider the variance of $\tilde{\varepsilon}_{t+1}$ :

$$
\begin{aligned}
\Psi\left(X_{t}\right) \equiv & \mathbb{E}_{t} \tilde{\varepsilon}_{t+1} \tilde{\varepsilon}_{t+1}^{\prime} \\
= & \mathbb{E}_{t} \tilde{x}_{t+1} \tilde{x}_{t+1}^{\prime}-\mathbb{E}_{t} \tilde{x}_{t+1} \mathbb{E}_{t} \tilde{x}_{t+1}^{\prime} \\
= & \mathbb{E}_{t} \tilde{x}_{t+1} \tilde{x}_{t+1}^{\prime}-\left(\frac{1}{2} D \Sigma_{0}+\left[\left(\Phi_{0} \otimes I\right)+\left(I \otimes \Phi_{0}\right)\right] x_{t}+\left[I-\left(\left(\Phi_{1} \otimes I\right)+\left(I \otimes \Phi_{1}\right)\right)+\frac{1}{2} D \Sigma_{1}\right] \tilde{x}_{t}\right) \\
& \times\left(\frac{1}{2} \Sigma_{0}^{\prime} D^{\prime}+x_{t}^{\prime}\left[\left(\Phi_{0} \otimes I\right)+\left(I \otimes \Phi_{0}\right)\right]^{\prime}+\tilde{x}_{t}^{\prime}\left[I-\left(\left(\Phi_{1} \otimes I\right)+\left(I \otimes \Phi_{1}\right)\right)+\frac{1}{2} D \Sigma_{1}\right]^{\prime}\right), \\
\cong & -\frac{1}{2} D \Sigma_{0}\left(\frac{1}{2} \Sigma_{0}^{\prime} D^{\prime}+x_{t}^{\prime}\left[\left(\Phi_{0} \otimes I\right)+\left(I \otimes \Phi_{0}\right)\right]^{\prime}+\tilde{x}_{t}^{\prime}\left[I-\left(\left(\Phi_{1} \otimes I\right)+\left(I \otimes \Phi_{1}\right)\right)+\frac{1}{2} D \Sigma_{1}\right]^{\prime}\right) \\
& -\left[\left(\Phi_{0} \otimes I\right)+\left(I \otimes \Phi_{0}\right)\right] x_{t}\left(\frac{1}{2} \Sigma_{0}^{\prime} D^{\prime}+x_{t}^{\prime}\left[\left(\Phi_{0} \otimes I\right)+\left(I \otimes \Phi_{0}\right)\right]^{\prime}\right) \\
& -\left[I-\left(\left(\Phi_{1} \otimes I\right)+\left(I \otimes \Phi_{1}\right)\right)+\frac{1}{2} \mathbb{D} \Sigma_{1}\right] \tilde{x}_{t} \frac{1}{2} \Sigma_{0}^{\prime} D^{\prime} \\
= & -\frac{1}{4} D \Sigma_{0} \Sigma_{0}^{\prime} D^{\prime}-\frac{1}{2} D \Sigma_{0} x_{t}^{\prime}\left[\left(\Phi_{0} \otimes I\right)+\left(I \otimes \Phi_{0}\right)\right]^{\prime}-\frac{1}{2}\left[\left(\Phi_{0} \otimes I\right)+\left(I \otimes \Phi_{0}\right)\right] x_{t} \Sigma_{0}^{\prime} D^{\prime} \\
& -\frac{1}{2} D \Sigma_{0} \tilde{x}_{t}^{\prime}\left[I-\left(\left(\Phi_{1} \otimes I\right)+\left(I \otimes \Phi_{1}\right)\right)+\frac{1}{2} D \Sigma_{1}\right]^{\prime} \\
& -\left[\left(\Phi_{0} \otimes I\right)+\left(I \otimes \Phi_{0}\right)\right] x_{t} x_{t}^{\prime}\left[\left(\Phi_{0} \otimes I\right)+\left(I \otimes \Phi_{0}\right)\right]^{\prime} \\
& -\frac{1}{2}\left[I-\left(\left(\Phi_{1} \otimes I\right)+\left(I \otimes \Phi_{1}\right)\right)+\frac{1}{2} D \Sigma_{1}\right] \tilde{x}_{t} \Sigma_{0}^{\prime} D^{\prime} .
\end{aligned}
$$

Hence,

$$
\begin{aligned}
\operatorname{vec}\left(\Psi\left(X_{t}\right)\right)= & \Psi_{0}+\Psi_{1} x_{t}+\Psi_{2} \tilde{x}_{t} \\
\Psi_{0}= & -\frac{1}{4}\left(D \Sigma_{0} \otimes D \Sigma_{0}\right) \operatorname{vec}(I), \\
\Psi_{1}= & -\frac{1}{2}\left(\left[\left(\Phi_{0} \otimes I\right)+\left(I \otimes \Phi_{0}\right)\right] \otimes D \Sigma_{0}\right)-\frac{1}{2}\left(D \Sigma_{0} \otimes\left[\left(\Phi_{0} \otimes I\right)+\left(I \otimes \Phi_{0}\right)\right]\right) \\
\Psi_{2}= & -\frac{1}{2}\left[I-\left(\left(\Phi_{1} \otimes I\right)+\left(I \otimes \Phi_{1}\right)\right)+\frac{1}{2} D \Sigma_{1}\right] \otimes D \Sigma_{0} \\
& -\frac{1}{2}\left(D \Sigma_{0} \otimes\left[I-\left(\left(\Phi_{1} \otimes I\right)+\left(I \otimes \Phi_{1}\right)\right)+\frac{1}{2} D \Sigma_{1}\right]\right) \\
& -\left[\left(\Phi_{0} \otimes I\right)+\left(I \otimes \Phi_{0}\right)\right] \otimes\left[\left(\Phi_{0} \otimes I\right)+\left(I \otimes \Phi_{0}\right)\right] .
\end{aligned}
$$




\section{A.3 Derivation of Results R1 and R2}

Let $m_{t}=\pi_{m} X_{t}$ and $n_{t}=\pi_{n} X_{t}$ for two variables $m_{t}$ and $n_{t}$. We want to find the conditional covariance between the two:

$$
\begin{aligned}
\mathbb{C} \mathbb{V}_{t}\left(m_{t+1}, n_{t+1}\right)= & {\left[\begin{array}{lll}
\pi_{m}^{0} & \pi_{m}^{1} & \pi_{m}^{2}
\end{array}\right]\left[\begin{array}{ccc}
0 & 0 & 0 \\
0 & \Omega\left(X_{t}\right) & \Gamma\left(X_{t}\right) \\
0 & \Gamma\left(X_{t}\right)^{\prime} & \Psi\left(X_{t}\right)
\end{array}\right]\left[\begin{array}{c}
\pi_{n}^{0 \prime} \\
\pi_{n}^{1 \prime} \\
\pi_{n}^{2 \prime}
\end{array}\right], } \\
= & \pi_{m}^{1} \Omega\left(X_{t}\right) \pi_{n}^{1 \prime}+\pi_{m}^{2} \Gamma\left(X_{t}\right)^{\prime} \pi_{n}^{1 \prime}+\pi_{m}^{1} \Gamma\left(X_{t}\right) \pi_{n}^{2 \prime}+\pi_{m}^{2} \Psi\left(X_{t}\right) \pi_{n}^{2 \prime}, \\
= & \left(\pi_{n}^{1} \otimes \pi_{m}^{1}\right) \operatorname{vec}\left(\Omega\left(X_{t}\right)\right)+\left(\pi_{n}^{1} \otimes \pi_{m}^{2}\right) \operatorname{vec}\left(\Gamma\left(X_{t}\right)^{\prime}\right) \\
& +\left(\pi_{n}^{2} \otimes \pi_{m}^{1}\right) \operatorname{vec}\left(\Gamma\left(X_{t}\right)\right)+\left(\pi_{n}^{2} \otimes \pi_{m}^{2}\right) \operatorname{vec}\left(\Psi\left(X_{t}\right)\right) \\
= & \left(\pi_{n}^{1} \otimes \pi_{m}^{1}\right) \Sigma_{0}+\left(\pi_{n}^{1} \otimes \pi_{m}^{2}\right) \Lambda_{0}+\left(\pi_{n}^{2} \otimes \pi_{m}^{1}\right) \Gamma_{0}+\left(\pi_{n}^{2} \otimes \pi_{m}^{2}\right) \Psi_{0} \\
& +\left(\left(\pi_{n}^{1} \otimes \pi_{m}^{2}\right) \Lambda_{1}+\left(\pi_{n}^{2} \otimes \pi_{m}^{1}\right) \Gamma_{1}+\left(\pi_{n}^{2} \otimes \pi_{m}^{2}\right) \Psi_{1}\right) x_{t} \\
& +\left(\left(\pi_{n}^{1} \otimes \pi_{m}^{1}\right) \Sigma_{1}+\left(\pi_{n}^{1} \otimes \pi_{m}^{2}\right) \Lambda_{2}+\left(\pi_{n}^{2} \otimes \pi_{m}^{1}\right) \Gamma_{2}+\left(\pi_{n}^{2} \otimes \pi_{m}^{2}\right) \Psi_{2}\right) \tilde{x}_{t} .
\end{aligned}
$$

So, to summarize,

$$
\begin{aligned}
& \mathbb{C V}_{t}\left(m_{t+1}, n_{t+1}\right)=\mathcal{A}\left(\pi_{m}, \pi_{n}\right) X_{t} \\
& \mathcal{A}\left(\pi_{m}, \pi_{n}\right)=\left[\begin{array}{lll}
\mathcal{A}_{m, n}^{0} & \mathcal{A}_{m, n}^{1} & \mathcal{A}_{m, n}^{2}
\end{array}\right] \\
& \mathcal{A}_{m, n}^{0}=\left(\pi_{n}^{1} \otimes \pi_{m}^{1}\right) \Sigma_{0}+\left(\pi_{n}^{1} \otimes \pi_{m}^{2}\right) \Lambda_{0}+\left(\pi_{n}^{2} \otimes \pi_{m}^{1}\right) \Gamma_{0}+\left(\pi_{n}^{2} \otimes \pi_{m}^{2}\right) \Psi_{0}, \\
& \mathcal{A}_{m, n}^{1}=\left(\pi_{n}^{1} \otimes \pi_{m}^{2}\right) \Lambda_{1}+\left(\pi_{n}^{2} \otimes \pi_{m}^{1}\right) \Gamma_{1}+\left(\pi_{n}^{2} \otimes \pi_{m}^{2}\right) \Psi_{1}, \\
& \mathcal{A}_{m, n}^{2}=\left(\pi_{n}^{1} \otimes \pi_{m}^{1}\right) \Sigma_{1}+\left(\pi_{n}^{1} \otimes \pi_{m}^{2}\right) \Lambda_{2}+\left(\pi_{n}^{2} \otimes \pi_{m}^{1}\right) \Gamma_{2}+\left(\pi_{n}^{2} \otimes \pi_{m}^{2}\right) \Psi_{2} .
\end{aligned}
$$

To obtain the products of vectors involving the state vector $X_{t}$, we note that

$$
\begin{aligned}
\pi_{m} X_{t} X_{t}^{\prime} \pi_{n}^{\prime}= & {\left[\begin{array}{lll}
\pi_{m}^{0} & \pi_{m}^{1} & \pi_{m}^{2}
\end{array}\right]\left[\begin{array}{ccc}
1 & x_{t}^{\prime} & \tilde{x}_{t}^{\prime} \\
x_{t} & x_{t} x_{t}^{\prime} & 0 \\
\tilde{x}_{t} & 0 & 0
\end{array}\right]\left[\begin{array}{c}
\pi_{n}^{0 \prime} \\
\pi_{n}^{1 \prime} \\
\pi_{n}^{2 \prime}
\end{array}\right] } \\
= & \left(\pi_{m}^{0}+\pi_{m}^{1} x_{t}+\pi_{m}^{2} \tilde{x}_{t}\right) \pi_{n}^{0 \prime}+\left(\pi_{m}^{0} x_{t}^{\prime}+\pi_{m}^{1} x_{t} x_{t}^{\prime}\right) \pi_{n}^{1 \prime}+\pi_{m}^{0} \tilde{x}_{t}^{\prime} \pi_{n}^{2 \prime}, \\
= & \left(\pi_{n}^{0} \otimes \pi_{m}^{0}\right)+\left(\pi_{n}^{0} \otimes \pi_{m}^{1}\right) x_{t}+\left(\pi_{n}^{0} \otimes \pi_{m}^{2}\right) \tilde{x}_{t}+\left(\pi_{n}^{1} \otimes \pi_{m}^{0}\right) x_{t} \\
& +\left(\pi_{n}^{1} \otimes \pi_{m}^{1}\right) \tilde{x}_{t}+\left(\pi_{n}^{2} \otimes \pi_{m}^{0}\right) \tilde{x}_{t} .
\end{aligned}
$$




\section{Hence}

$$
\begin{aligned}
& \pi_{m} X_{t} X_{t}^{\prime} \pi_{n}^{\prime}=\mathcal{B}\left(\pi_{m}, \pi_{n}\right) X_{t}, \\
& \mathcal{B}\left(\pi_{m}, \pi_{n}\right)=\left[\begin{array}{lll}
\mathcal{B}_{m, n}^{0} & \mathcal{B}_{m, n}^{1} & \mathcal{B}_{m, n}^{2}
\end{array}\right], \\
& \mathcal{B}_{m, n}^{0}=\left(\pi_{n}^{0} \otimes \pi_{m}^{0}\right) \operatorname{vec}(I)=\operatorname{vec}\left(\pi_{n}^{0} * \pi_{m}^{0}\right), \\
& \mathcal{B}_{m, n}^{1}=\left(\pi_{n}^{0} \otimes \pi_{m}^{1}\right)+\left(\pi_{n}^{1} \otimes \pi_{m}^{0}\right), \\
& \mathcal{B}_{m, n}^{2}=\left(\pi_{n}^{0} \otimes \pi_{m}^{2}\right)+\left(\pi_{n}^{1} \otimes \pi_{m}^{1}\right)+\left(\pi_{n}^{2} \otimes \pi_{m}^{0}\right) .
\end{aligned}
$$

